\title{
Structural Characteristics of T-PARC Typhoon Sinlaku during Its Extratropical Transition
}

\author{
JULIAN F. QUINTING \\ Institute for Meteorology and Climate Research, Karlsruhe Institute of Technology, Karlsruhe, Germany \\ Michael M. BELL* AND PATRICK A. HARR \\ Department of Meteorology, Naval Postgraduate School, Monterey, California \\ SARAH C. JONES ${ }^{+}$ \\ Institute for Meteorology and Climate Research, Karlsruhe Institute of Technology, Karlsruhe, Germany
}

(Manuscript received 28 September 2013, in final form 27 December 2013)

\begin{abstract}
The structure and the environment of Typhoon Sinlaku (2008) were investigated during its life cycle in The Observing System Research and Predictability Experiment (THORPEX) Pacific Asian Regional Campaign (T-PARC). On 20 September 2008, during the transformation stage of Sinlaku's extratropical transition (ET), research aircraft equipped with dual-Doppler radar and dropsondes documented the structure of the convection surrounding Sinlaku and low-level frontogenetical processes. The observational data obtained were assimilated with the recently developed Spline Analysis at Mesoscale Utilizing Radar and Aircraft Instrumentation (SAMURAI) software tool. The resulting analysis provides detailed insight into the ET system and allows specific features of the system to be identified, including deep convection, a stratiform precipitation region, warm- and cold-frontal structures, and a dry intrusion. The analysis offers valuable information about the interaction of the features identified within the transitioning tropical cyclone. The existence of dry midlatitude air above warm-moist tropical air led to strong potential instability. Quasigeostrophic diagnostics suggest that forced ascent during warm frontogenesis triggered the deep convective development in this potentially unstable environment. The deep convection itself produced a positive potential vorticity anomaly at midlevels that modified the environmental flow. A comparison of the operational ECMWF analysis and the observation-based SAMURAI analysis exhibits important differences. In particular, the ECMWF analysis does not capture the deep convection adequately. The nonexistence of the deep convection has considerable implications on the potential vorticity structure of the remnants of the typhoon at midlevels. An inaccurate representation of the thermodynamic structure of the dry intrusion has considerable implications on the frontogenesis and the quasigeostrophic forcing.
\end{abstract}

\section{Introduction}

About $45 \%$ of tropical cyclones (TCs) interact with the midlatitude flow after recurvature (Jones et al. 2003) and undergo extratropical transition (ET), with over

\footnotetext{
* Current affiliation: Department of Meteorology, University of Hawaii at Manoa, Honolulu, Hawaii.

${ }^{+}$Current affiliation: Deutscher Wetterdienst, Offenbach, Germany.

Corresponding author address: Julian F. Quinting, Institute for Meteorology and Climate Research (IMK-TRO), Karlsruhe Institute of Technology, Kaiserstr. 12, 76131 Karlsruhe, Germany. E-mail: julian.quinting@kit.edu
}

$50 \%$ of these storms reintensifying as extratropical cyclones in the North Atlantic basin (Hart and Evans 2001). The ET process is determined by structural changes of a TC and can be considered generally as a transformation from a symmetric warm-core TC to an asymmetric cold-core cyclone. Evans et al. (2006) showed that operational global numerical models do not properly simulate these structural changes. However, the dynamical processes that are associated with these structural changes perturb the midlatitude flow. In idealized simulations Riemer et al. (2008) showed that these complex perturbations to the midlatitude flow may result in a baroclinic downstream development. Real case ensemble forecasts indicate that initially small perturbations may lead to plumes of forecast uncertainty 
in downstream regions (Anwender et al. 2008; Reynolds et al. 2009). Therefore, ET does not only affect those regions in the vicinity of the ET event but also regions far downstream (Agusti-Panareda et al. 2004; Archambault et al. 2007; Cordeira and Bosart 2010; Grams et al. 2011).

Only a small number of ET events have been investigated by aircraft-based measurements. Therefore, most studies on ET were limited to model data or to satellite-based observations. In an examination of $30 \mathrm{ET}$ cases Klein et al. (2000) divided the ET process into a transformation stage and a reintensification stage. Based on infrared satellite imagery, they showed that the transformation stage is characterized by the interaction of a TC and the midlatitude baroclinic zone. Vancas (2006) utilized temperature retrievals from the Advanced Microwave Sounding Unit to investigate the thermal characteristics of the atmosphere in the vicinity of one ET event. Based on these retrievals, Vancas (2006) identified cold air to the west and warm air to the east during the interaction of the TC and the midlatitude baroclinic zone.

This interaction involves lower-tropospheric temperature advection, the deformation of the TC warm core, lower-tropospheric frontogenesis, and slantwise ascent (descent) to the east (west) of the TC in a baroclinic environment (Harr and Elsberry 2000; Harr et al. 2000). Harr and Elsberry (2000) showed that the modification of the equivalent potential temperature gradient during the transformation stage results in warm frontogenesis in the northeastern quadrant of the transitioning TC. Furthermore, they found that cold frontogenesis to the west of the TC is often suppressed as a result of a thermally direct circulation including the descent of cold air from upstream of the cyclone. In an investigation of the ET of Hurricane Floyd (1999), Atallah and Bosart (2003) showed that the dynamics of ET can be represented in a quasigeostrophic framework. In their study, the Sutcliffe approximation of the quasigeostrophic omega equation provided an accurate physical explanation of the evolution of the precipitation distribution during ET. Agusti-Panareda et al. (2004) derived a potential vorticity (PV)-based conceptual model of the processes involved in ET. They suggested that the moisture that is collocated with the TC and that is advected by its circulation is spread over the warm sector of the cyclone, leading to a short-lived convective development with associated diabatically generated $\mathrm{PV}$. Agusti-Panareda et al. (2004) stated that the convective burst might be crucial for maintaining the diabatically produced PV tower associated with the TC. They suggested that when the burst of deep convection weakens, the diabatically produced PV tower is not supported any longer as latent heat release stops maintaining the positive PV anomaly at low levels.
The first aircraft measurements during ET were accomplished in 2000 by the Meteorological Service of Canada and the Canadian National Research Council inside Hurricanes Michael and Karen (Wolde et al. 2001; Abraham et al. 2004). The data from these research flights identified asymmetries in moisture and winds associated with the ET systems. A further observing study involving research flights into the ET of Tropical Storm Ophelia was accomplished in the Hurricane Field Program of 2005 (Fogarty 2006; Rogers et al. 2006). As part of the Intensity Forecasting Experiment (IFEX) the structure of Ophelia was investigated from genesis to ET by research aircraft and aerosondes. During the ET of Ophelia, two National Oceanic and Atmospheric Administration (NOAA) P-3 flights sampled for the first time the core dynamical structure and structural changes of an ET system using airborne Doppler radar and dropsondes. The observations showed that the upper portion of Ophelia's circulation was sheared away by strong upper-level winds. Findings from the research flights also indicated the intrusion of dry, midlatitude air. However, high-resolution observations of the structural changes of a TC during ET and its environment are still rare and have not been investigated yet in detail.

One of the aims of The Observing System Research and Predictability Experiment (THORPEX) Pacific Asian Regional Campaign (T-PARC) in 2008 was to extend the knowledge of the various physical processes involved in ET using aircraft observations. During this field campaign one of the major typhoons in the western North Pacific Ocean in 2008, Typhoon (TY) Sinlaku, was investigated from tropical cyclogenesis until ET. In total 28 research flights were carried out by four research aircraft during the life cycle of TY Sinlaku.

TY Sinlaku developed in the western North Pacific, strengthened quickly to typhoon intensity, and recurved to the north of Taiwan on 14 September. Moving eastnortheastward, the cyclone weakened to a tropical storm on 16 September. A very asymmetric structure indicated that Sinlaku had entered the transformation stage of ET. However, instead of completing transformation, Sinlaku reintensified (Sanabia 2010) and regained typhoon intensity on 19 September (Foerster et al. 2013, manuscript submitted to Mon. Wea. Rev.). At that time, Sinlaku exhibited a partial eyewall around the low-level circulation maximum that is here defined as the low-level center. The focus of the current study is 20 September when Sinlaku approached the primary midlatitude baroclinic zone to enter the final stage of ET. Sinlaku decayed in the Pacific over several days with continued convective activity. 
The outline of this study is as follows. In section 2, we present the data and methodology employed, and in section 3 we describe the synoptic situation during the ET of Sinlaku. We show observational data from T-PARC focusing on structural characteristics in section 4 , and on possible mechanisms for producing the observed structure in section 5 . In addition, we investigate the representation of structural characteristics and mechanisms in the operational European Centre for MediumRange Weather Forecasts (ECMWF) analysis and compare it to the observational analysis. The study ends with a discussion in section 6 .

\section{Dataset and methodology}

The goals of the T-PARC missions on 19 and 20 September were to document structural changes in the convection of the cyclone as its ET progressed, to investigate the interaction between Sinlaku and the midlatitude flow, and to investigate the development of frontal structures. For the first time, airborne observations were collected simultaneously by three research aircraft [Naval Research Laboratory-P3 (NRL-P3), U.S. Air Force-WC130 (USAF-WC130), and DLR-Falcon] during ET and provided unique and detailed insight into a TC approaching a midlatitude baroclinic zone. On 20 September the NRL-P3 and the USAF-WC130 measured the structure and the environment of a deep convective system that developed as Sinlaku was close to the primary midlatitude baroclinic zone.

The two aircraft investigated the structure of Sinlaku with the Electra Doppler Radar (ELDORA; Hildebrand et al. 1996) on the NRL-P3 and dropsondes released from the NRL-P3 and the USAF-WC130. In particular, the use of ELDORA provides a high-resolution, threedimensional depiction of winds and reflectivity. The Doppler radar operates at a wavelength of $3.2 \mathrm{~cm}$ $(9.3 \mathrm{GHz})$, a peak power of $50 \mathrm{~kW}$, and a beamwidth of $1.8^{\circ}$. Two beams point $\sim 16^{\circ}$ fore and aft and overlap as the NRL-P3 translates through space.

Radar-derived radial winds from ELDORA, dropsonde winds and temperatures, and satellite-based atmospheric motion vectors were analyzed with the recently developed Spline Analysis at Mesoscale Utilizing Radar and Aircraft Instrumentation (SAMURAI) software tool (Bell et al. 2012). This tool is based on a three-dimensional variational data assimilation approach that analyzes observations of various airborne instruments to obtain the most probable kinematic and thermodynamic state of the atmosphere. SAMURAI minimizes an incremental cost function using a conjugate gradient algorithm (Polak 1971; Press et al. 2002). The technical details of SAMURAI are described further in Bell et al. (2012).

A domain of $400 \mathrm{~km} \times 400 \mathrm{~km} \times 15 \mathrm{~km}$ with a horizontal resolution of $4 \mathrm{~km} \times 4 \mathrm{~km}$ and a vertical resolution of $0.25 \mathrm{~km}$ was used for the analysis of the observational data on 20 September. The analysis was performed in a reference frame moving with the TC, with a time and space correction applied to the data assuming a linear storm motion between the times at which we have best track positions. The translation speed of Sinlaku was $10.5 \mathrm{~m} \mathrm{~s}^{-1}$ in the zonal direction and $0.6 \mathrm{~m} \mathrm{~s}^{-1}$ in the meridional direction at the reference time of 0600 UTC. The time and space correction shifted the data into a coordinate system relative to the moving storm center over a time period between 0500 and 0800 UTC.

The operational analysis of the ECMWF at 0600 UTC 20 September at a horizontal resolution of $0.25^{\circ} \times$ $0.25^{\circ}$ was used as a background estimate. The ECMWF analysis was interpolated to a $4 \mathrm{~km} \times 4 \mathrm{~km}$ grid using a Gaussian weighting function with a radius of influence of $30 \mathrm{~km}$. The following standard deviations of background errors for the ECMWF analysis were used: horizontal wind speed error of $15 \mathrm{~m} \mathrm{~s}^{-1}$, vertical wind speed error of $5 \mathrm{~m} \mathrm{~s}^{-1}$, temperature error of $15 \mathrm{~K}$, and specific humidity error of $5 \mathrm{~g} \mathrm{~kg}^{-1}$. The given errors smooth the transition between regions with high and low observational density and ensure that the SAMURAI analysis weights the observational data more heavily than the background field.

\section{Synoptic situation}

At 0600 UTC 20 September Sinlaku was located at $35.1^{\circ} \mathrm{N}, 144.7^{\circ} \mathrm{E}$ to the south of a nearly zonal upperlevel flow that constituted the southern branch of a split jet stream (Fig. 1). The two branches of the jet stream merged about $15^{\circ} \mathrm{E}$ of Sinlaku at the southern apex of an upper-level midlatitude trough. A low-level low pressure system associated with this trough was located to the northeast of Sinlaku at $52^{\circ} \mathrm{N}, 158^{\circ} \mathrm{E}$. The analyzed pattern with the major midlatitude low to the northeast of the TC was similar to the northeast pattern, which was described unfavorable for a reintensification in Harr et al. (2000). Immediately to the west and farther to the northwest of Sinlaku, two weak troughs could be identified in the upper troposphere. We assessed the influence of these troughs on Sinlaku by calculating the quasigeostrophic forcing for vertical motion from the ECMWF analysis (see Fig. 3.5 in Quinting 2011). The evaluation showed that these troughs did not cause an upper-level quasigeostrophic forcing for vertical motion and consequently did not produce favorable conditions for a reintensification of Sinlaku. 


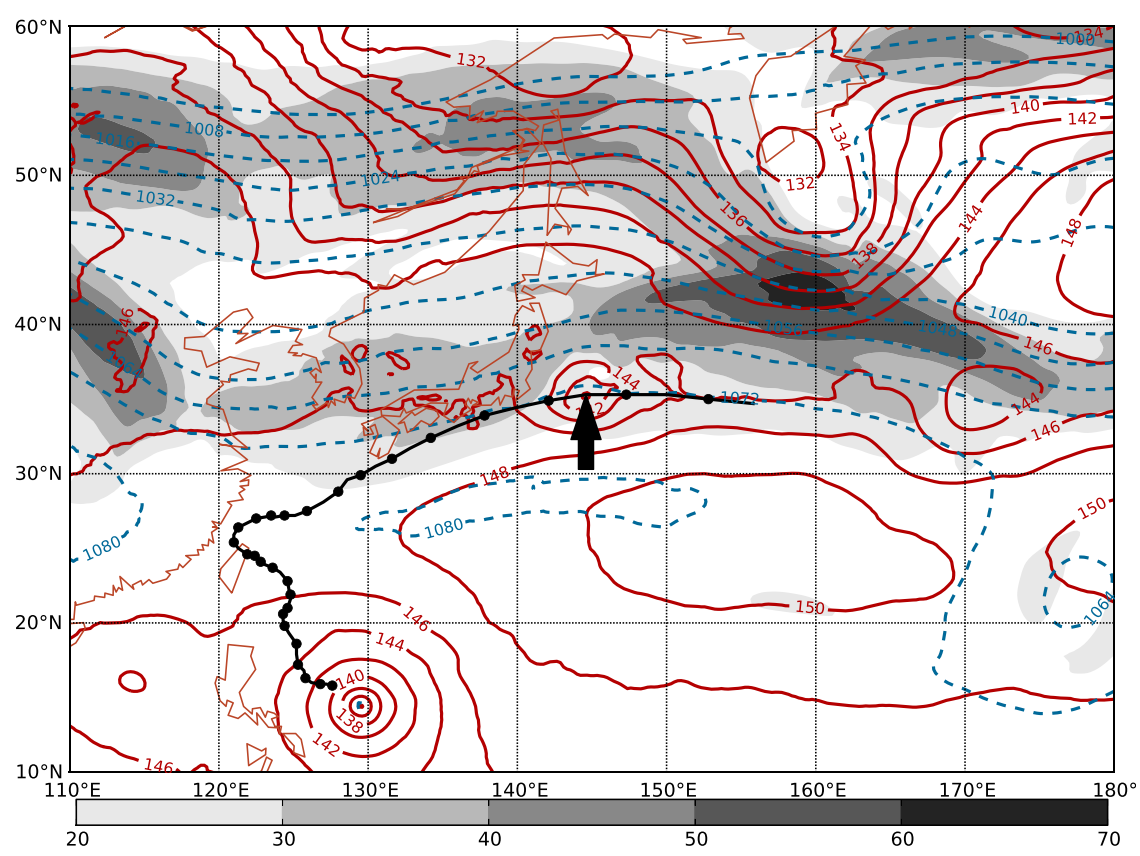

FIG. 1. Wind speed ( $\mathrm{m} \mathrm{s}^{-1}$; shaded) at $250 \mathrm{hPa}$, geopotential (gpdam) at $850 \mathrm{hPa}$ in red solid contours, and geopotential at $250 \mathrm{hPa}$ in blue dashed contours from operational ECMWF analysis at 0600 UTC 20 Sep. The black line represents best track of Sinlaku (Source: Japan Meteorological Agency). The arrow indicates the position of Sinlaku at 0600 UTC 20 Sep.

In the satellite imagery (Fig. 2) a broad cirrus shield with a sharp edge to the northeast of the low-level center of Sinlaku indicated that the cyclone was in the transformation stage of ET (Klein et al. 2000). This feature marked the confluence of the cyclone outflow with the midlatitude jet to the north. Between 19 and 20 September, infrared (Fig. 2a) and water vapor satellite imagery (not shown) indicated a tongue of midtropospheric dry air wrapping around the low-level center of Sinlaku. At 0000 UTC 20 September, this dry air reached the

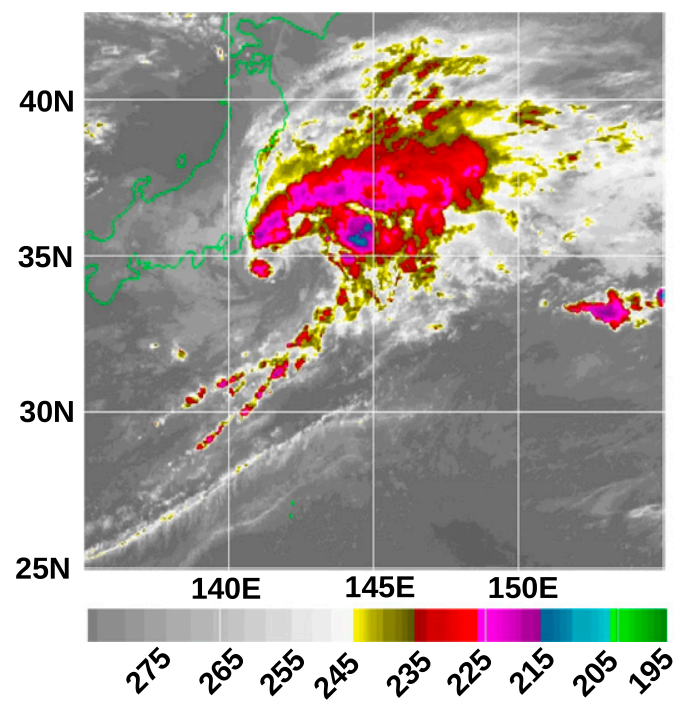

(a) 2130 UTC 19 September

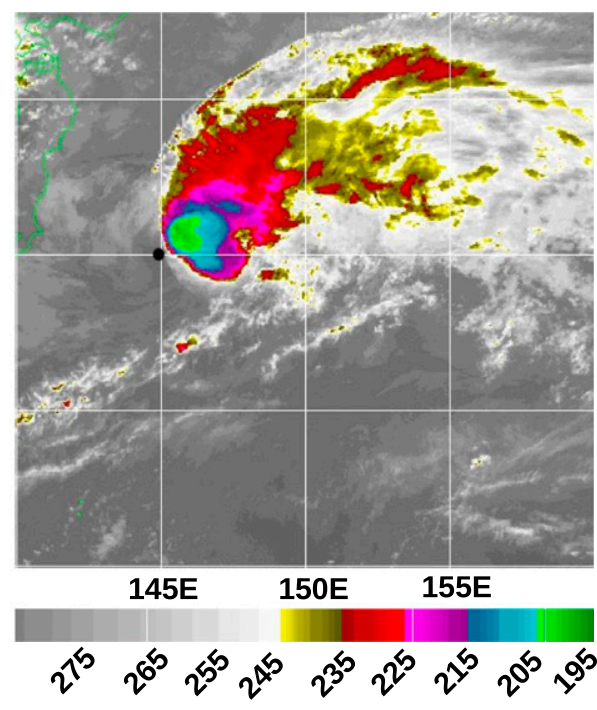

(b) 0630 UTC 20 September

FIG. 2. (a),(b) Multifunctional Transport Satellite (MTSAT) IR brightness temperature (K) (Source: NCAR/ EOL), the black dot in (b) highlights the position of the low-level circulation center. 


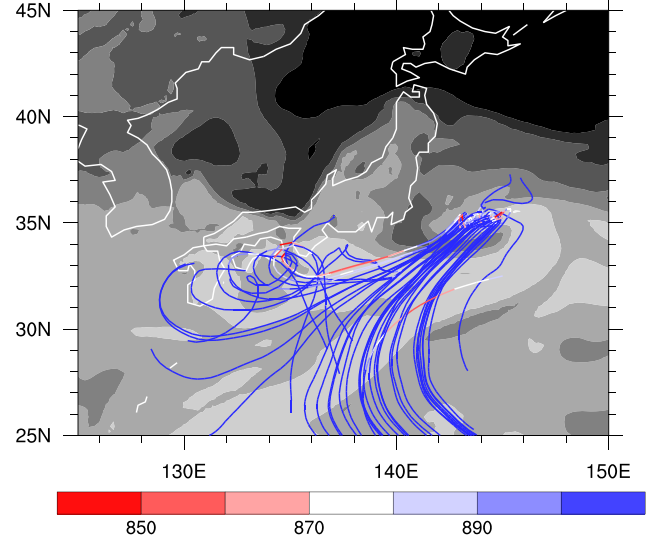

(a)

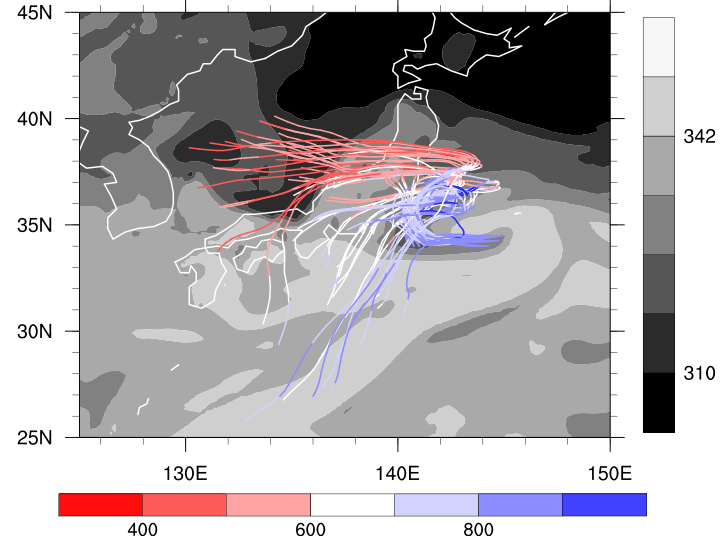

(b)

FIG. 3. Equivalent potential temperature (K) at $850 \mathrm{hPa}$ at 0600 UTC 20 Sep (gray shading, vertical color bar) and 48-h backward trajectories ending in Sinlaku's environment at 0600 UTC 20 Sep with specific humidity (a) greater than $14 \mathrm{~g} \mathrm{~kg}^{-1}$ and (b) less than $7 \mathrm{~g} \mathrm{~kg}^{-1}$ at the final time. Color along trajectories denotes pressure (hPa; horizontal color bar).

eastern side of the low-level center. Deep convection developed rapidly on the leading edge of this dry air to the east of Sinlaku's low-level center (Fig. 2b). In a time period of $1 \mathrm{~h}$, the brightness temperature decreased from $233 \mathrm{~K}$ to values of about $195 \mathrm{~K}$ and an almost circular expansion of cold cloud tops indicated intense convective development. The system maintained its intensity until 0800 UTC 20 September and decayed as it moved eastward. During the decay of Sinlaku, satellite imagery indicated that the convective activity became separated from the low-level center (not shown).

In the ECMWF analysis, a marked area of warmmoist air surrounded a dry intrusion at $850 \mathrm{hPa}$ at 0600 UTC 20 September (Fig. 3). The belt of warmmoist air with equivalent potential temperatures exceeding $340 \mathrm{~K}$ extended from the subtropics and the south of Japan toward the circulation center of Sinlaku at $35.1^{\circ} \mathrm{N}, 144.7^{\circ} \mathrm{E}$. The tongue of dry air was identified in the ECMWF analysis as a region of equivalent potential temperature lower than $330 \mathrm{~K}$ between $34^{\circ}-35^{\circ} \mathrm{N}$ and $140^{\circ}-145^{\circ} \mathrm{E}$. To evaluate the origin of the air masses being advected toward the cyclone at 0600 UTC 20 September, 48-h backward trajectories were calculated from 6-hourly operational ECMWF analyses using the method of Wernli and Davies (1997). The trajectories were calculated with a temporal resolution of one hour ending in a domain from $140^{\circ}$ to $145^{\circ} \mathrm{E}$ and from $32.5^{\circ}$ to $37.5^{\circ} \mathrm{N}$ between 900 and $800 \mathrm{hPa}$.

Important aspects with respect to the convective development are the origin of dry air wrapping around the low-level center of Sinlaku between 19 and 20 September, and the origin of warm-moist air being advected at low levels into the region of the convective event. The characteristics of the moist air were defined by calculating only those trajectories that exceeded a specific humidity of $14 \mathrm{~g} \mathrm{~kg}^{-1}$ at the final time (Fig. 3a). Parcels moving along these trajectories crossed a region with high equivalent potential temperatures as they passed around the subtropical ridge. The set of trajectories that approached the convective area from the south represent one source region. The second source region is defined by trajectories that originated near the coast of Japan. Cyclonic trajectories indicate that the parcels following these trajectories already passed the cyclone circulation but did not ascend into the upper-level flow. As a result the parcels passed through the cyclone circulation twice: between 0000 and 1200 UTC 19 September and again at 0600 UTC 20 September.

The characteristics of the dry intrusion are specified by calculating only descending trajectories that do not exceed a specific humidity of $7 \mathrm{~g} \mathrm{~kg}^{-1}$ at the final time. The majority of air parcels meeting these criteria had their origin over Japan and the Sea of Japan (Fig. 3b). During the first hours of the trajectory calculation, the air parcels had a nearly constant height between 400 and $600 \mathrm{hPa}$ and were advected eastward in a zonally oriented flow. At about $140^{\circ} \mathrm{E}$, the air parcels turned southward and descended rapidly to about $800 \mathrm{hPa}$. This descent was likely forced by cold-air advection west of the typhoon.

The airflow characteristics strongly resemble those of midlatitude wave cyclones (Carlson 1980). The warmmoist southerly inflow from the subtropics can be interpreted as a warm conveyor belt that reached the system at low levels and ascended east of the cyclone in northerly directions. The warm conveyor belt-like 


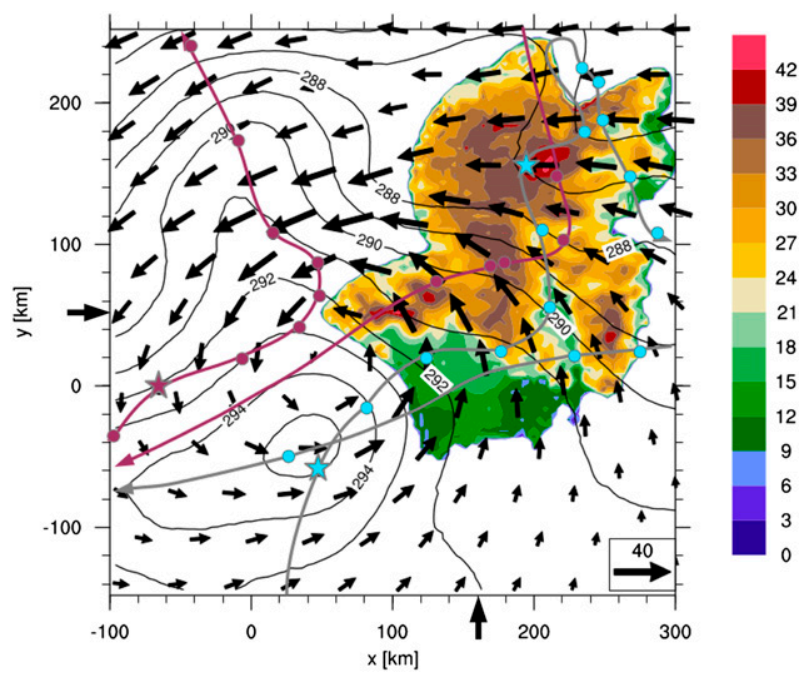

FIG. 4. Overview of the analyzed domain and the spatial distribution of observational data. Maximum reflectivities between 0 and $15 \mathrm{~km}$ (dBZ; shaded) and temperature ( $\mathrm{K}$; contours) at $1.5 \mathrm{~km}$. Wind vectors give horizontal wind at $1.5 \mathrm{~km}\left(\mathrm{~m} \mathrm{~s}^{-1}\right)$. Gray line denotes flight track of the NRL-P3 and red line denotes flight track of the USAF-WC130. Filled circles give positions of dropsondes included in SAMURAI analysis. Stars indicate positions of dropsondes in Fig. 7. Coordinates are relative to the best track position at 0600 UTC 20 Sep in this and in the following figures. Black arrows at coordinate axis show positions of cross sections in Fig. 6.

structure interacted to the south and southeast of the cyclone center with a tongue of dry midlatitude air. The flow of air parcels in the dry intrusion $(850 \mathrm{hPa})$ over the air parcels in a moist southerly flow near the surface (below $900 \mathrm{hPa}$ ) led to a significant destabilization and hence favored the conditions for convective activity. The intensity of the deep convective system, as illustrated by the satellite imagery, indicated remnant TC characteristics.

\section{Structural characteristics}

In this section the mesoscale structure of Sinlaku and its environment is documented by the use of the SAMURAI analysis and single dropsonde profiles. The analysis provides a detailed depiction of the dynamic and thermodynamic structure of Sinlaku during its interaction with the primary midlatitude baroclinic zone. An overview of the analyzed domain and the spatial distribution of observational data is given in Fig. 4. The origin of this domain is the best track storm position at 0600 UTC 20 September $\left(35.1^{\circ} \mathrm{N}, 144.7^{\circ} \mathrm{E}\right)$. The reflectivity composite shows that most of the ELDORA data were collected to the east and northeast of the cyclone center. The convective system was larger than depicted in Fig. 4, but could not be fully explored

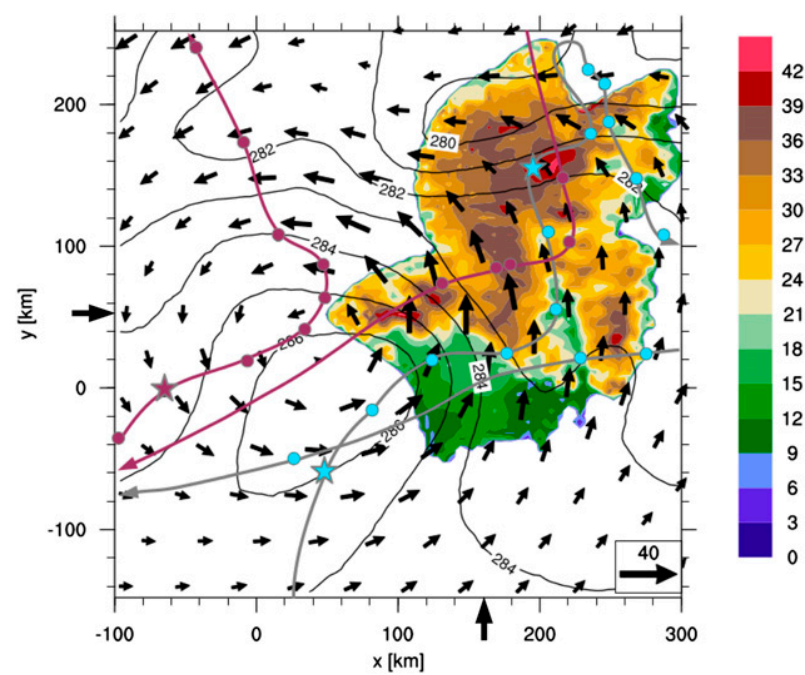

FIG. 5. As in Fig. 4, but temperature (K; contours) and horizontal wind $\left(\mathrm{m} \mathrm{s}^{-1}\right.$; vectors) at $3 \mathrm{~km}$.

because of operational restrictions of the NRL-P3. In addition to the ELDORA data, 21 dropsondes were released to the south and east of the circulation center by the NRL-P3 and the USAF-WC130. To the northwest, the dynamic and thermodynamic structure of Sinlaku and its environment was documented by nine USAF-WC130 dropsondes. Because of the restrictions on the flight level of the USAF-WC130 and the NRL-P3, dropsonde data were only available below $600 \mathrm{hPa}$.

Based on the SAMURAI analysis of Doppler and dropsonde winds, a closed circulation could be identified around Sinlaku at 1.5-km height (Fig. 4). The circulation center was about $10 \mathrm{~km}$ north and $50 \mathrm{~km}$ east of the best track center. Strongest winds occurred to the east and north of the low-level center with maximum winds of about $40 \mathrm{~m} \mathrm{~s}^{-1}$. The flow was southerly to southeasterly in the southern part of the convectively active region and easterly in the northern part. This horizontal wind shift produced a confluent zone between 50 and $120 \mathrm{~km}$ north and between 60 and $180 \mathrm{~km}$ east. The circulation was more symmetric at 3-km height (Fig. 5) than at 1.5$\mathrm{km}$ height (Fig. 4). The center of the circulation was displaced slightly to the northwest at $3 \mathrm{~km}$ compared to the low-level center. The confluent zone of southerly and easterly winds was shifted northward and is located between 160 and $240 \mathrm{~km}$ north.

The reflectivity pattern derived from the SAMURAI analysis contains maximum values of more than $42 \mathrm{dBZ}$ between 70 and $110 \mathrm{~km}$ east along $46 \mathrm{~km}$ north (i.e., over the southern portion of the convective system). Much lower values of reflectivity to the southeast of this region mark a cirrus shield that can be identified in vertical cross sections (see below). The reflectivity exceeds 


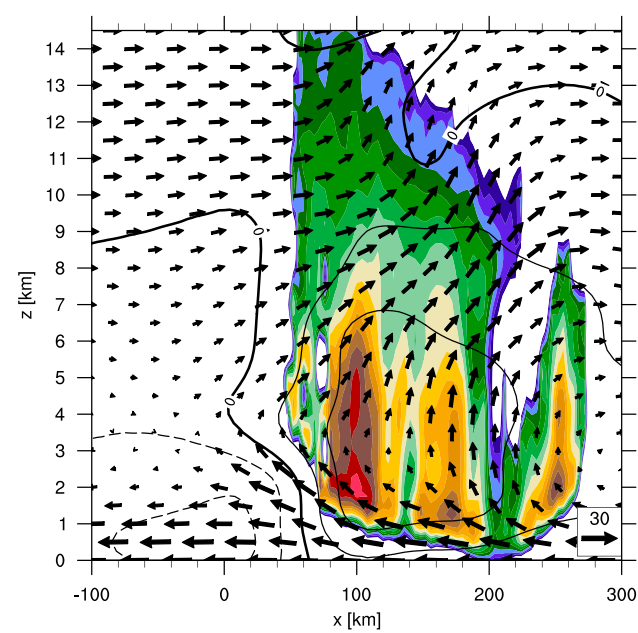

(a)

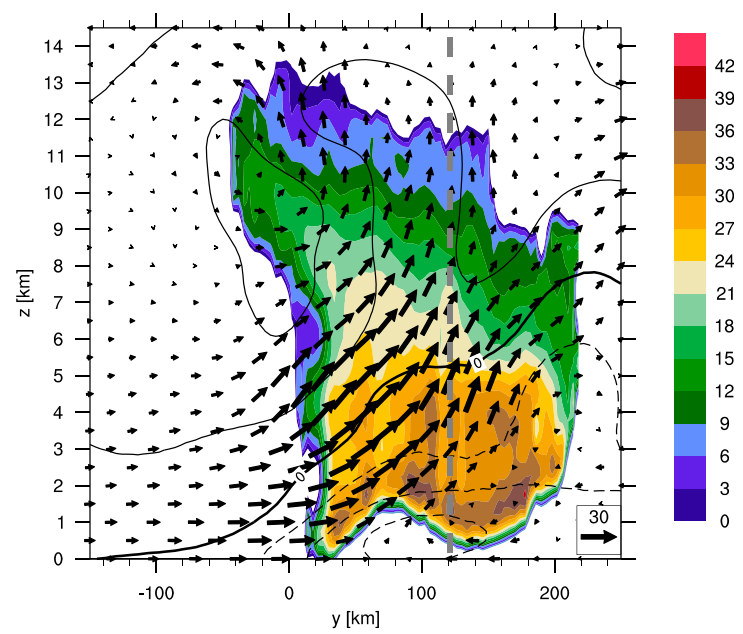

(b)

FIG. 6. Reflectivity (dBZ; shaded) along (a) $46 \mathrm{~km}$ north and (b) $160 \mathrm{~km}$ east. Wind vectors are parallel to the cross section $\left(\mathrm{m} \mathrm{s}^{-1}\right)$ with $w$ multiplied by a factor of 10 . Contours denote wind component perpendicular to the cross section ( $\mathrm{m} \mathrm{s}^{-1}$; contour interval of $10 \mathrm{~m} \mathrm{~s}^{-1}$ ). Dashed contours are negative values. The gray dashed line in (b) marks the transition from convective to stratiform precipitation.

$42 \mathrm{dBZ}$ in the northeastern part of the radar analysis region (at $200 \mathrm{~km}$ east and $150 \mathrm{~km}$ north).

Vertical cross sections are used in the following to illustrate the structure of the precipitation and the wind field. The elevation of the reflectivity pattern from the ground in the SAMURAI analysis in these cross sections (Fig. 6) results from the quality control process. In fact, precipitation existed at low levels but its signal was removed through ground clutter removal.

A vertical cross section from west to east through the region with high reflectivity along $46 \mathrm{~km}$ north (Fig. 6a) defines three cells of deep convection at 100, 170, and $250 \mathrm{~km}$ east where the $24-\mathrm{dB} Z$ isoline extends up to $8 \mathrm{~km}$. The $12-\mathrm{dB} Z$ isoline even extends up to $14.5 \mathrm{~km}$. The radar raw data [see Figs. 6.2 and 6.3 in Quinting (2011)] with a finer resolution than the SAMURAI analysis do not show a bright band in the reflectivity in this region. This nonexistence is an important contrast to the northern part of the radar analysis region that is shown in a vertical cross section from south to north along $160 \mathrm{~km}$ east (Fig. 6b). Several single convective cells can be identified between 20 and $120 \mathrm{~km}$ north. A broad cirrus shield extends to the south of these convective cells between 8 - and $13-\mathrm{km}$ height. North of $120 \mathrm{~km}$ north the reflectivity pattern is more homogeneous than the reflectivity pattern between 20 and $120 \mathrm{~km}$ north and single convective cells cannot be identified. Additionally, the $24-\mathrm{dBZ}$ isoline reaches only $6-\mathrm{km}$ height and is hence about $2 \mathrm{~km}$ lower than in the deep convective region. The reflectivity pattern of the radar raw data (not shown) exhibits a bright band in this region that indicates a stratiform precipitation region.
The existence of fall streaks in the radar raw data confirms the stratiform nature of the precipitation region. High reflectivity values between 80 and $180 \mathrm{~km}$ north and 1-3-km height in the SAMURAI analysis are related to these fall streaks. The reason for the absence of a bright band in the SAMURAI analysis is that the vertical and horizontal resolutions are too coarse to represent these features. The missing reflectivity near the ground is again the result of ground clutter removal.

The SAMURAI analysis of southerly inflow into the region of the deep convection (Fig. 6a) coincides with the southerly inflow that was documented in section 3 with the help of backward trajectories from the ECMWF analysis (Fig. 3a). The southerly component of the wind was strongest between 1- and 6-km height. Above 6-km height the wind shifted into westerlies, which produced an outflow along the eastern boundary of the convection. The lower altitudes of the convective (Fig. 6a) and stratiform (Fig. 6b) region is determined by an easterly wind component that reaches its maximum of more than $30 \mathrm{~m} \mathrm{~s}^{-1}$ between 60 and $140 \mathrm{~km}$ north (Fig. $6 \mathrm{~b})$. The increasing vertical extent of the layer with easterly winds in the northern part of the analyzed domain is noticeable. Dropsonde raw data (Fig. 7b) show this easterly wind layer and the wind shifts from easterly to southerly winds between 850 and $700 \mathrm{hPa}$. The veering winds with height in the SAMURAI analysis and in the dropsonde measurements suggest warm-air advection, which indicates the interaction of Sinlaku with a baroclinic zone and is suggestive of warm frontogenesis in this region. 


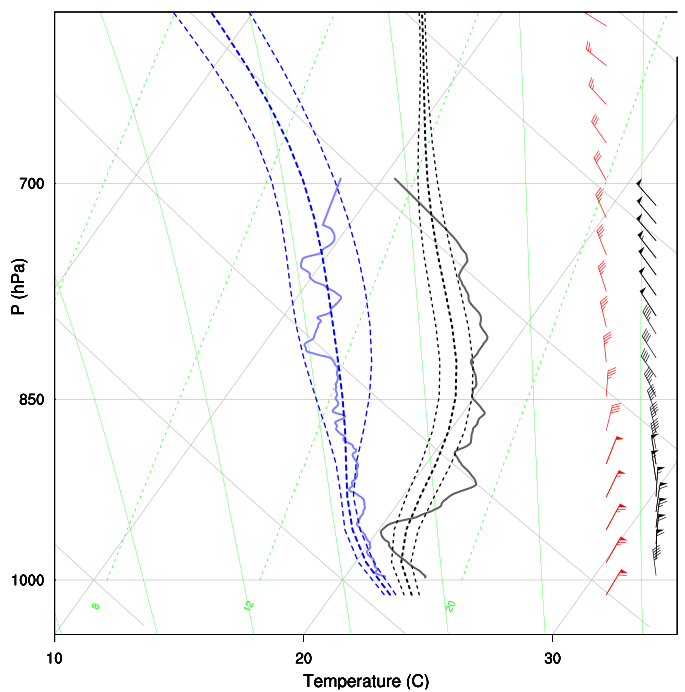

(a)

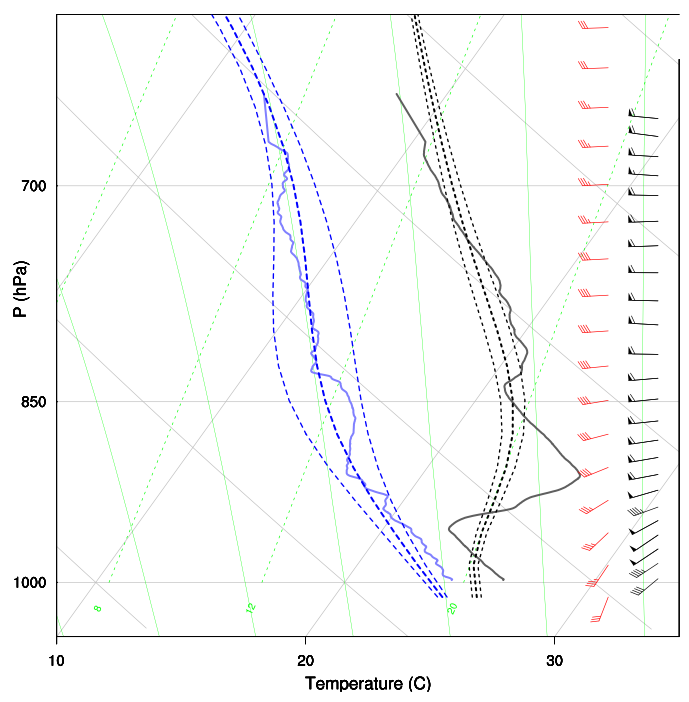

(c)

The southerly, lower-tropospheric inflow into the convective system south of $120 \mathrm{~km}$ north (Fig. 6b) ascended into the midtroposphere. Two branches of ascent can be distinguished above 5-km height. The first one ascends slantwise from the southerly flow at low levels and leaves the analyzed domain between 7- and $11-\mathrm{km}$ height at $250 \mathrm{~km}$ north. The second branch consists of nearly upright ascent throughout the complete troposphere up to the cirrus shield at $14.5-\mathrm{km}$ height between 0 and $150 \mathrm{~km}$ north.

The SAMURAI temperature field at $1.5 \mathrm{~km}$ indicates that Sinlaku was moving into a region of a south-north temperature gradient (Fig. 4). To the east of the lowlevel center, the temperature change reaches maximum values of $4 \mathrm{~K}$ over a distance of $70 \mathrm{~km}$ along $100 \mathrm{~km}$ east.

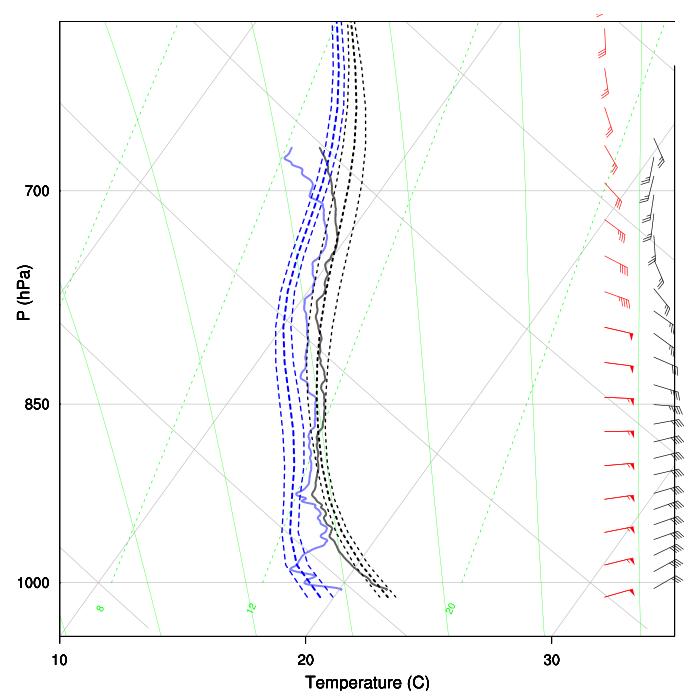

(b)

FIG. 7. Skew $T-\log p$ plot of measurements from dropsondes released from (a) USAF-WC130 at $70 \mathrm{~km}$ west and $0 \mathrm{~km}$ north at 0520 UTC, and from NRL-P3 at (b) $200 \mathrm{~km}$ east and $160 \mathrm{~km}$ north at 0652 UTC and (c) at $40 \mathrm{~km}$ east and $60 \mathrm{~km}$ south at 0616 UTC in comparison to SAMURAI analysis. Thick dashed lines show SAMURAI analysis (blue = dewpoint, black = temperature), thin dashed lines are the standard deviation of the SAMURAI analysis in a box of $24 \mathrm{~km} \times$ $24 \mathrm{~km}$ around the dropsonde location; solid lines are dropsonde measurements (blue $=$ dewpoint, black $=$ temperature). Red wind barbs are from SAMURAI analysis, black wind barbs are from dropsonde measurements.

This temperature gradient is accompanied by a horizontal wind shift of about $90^{\circ}$. To the west of the lowlevel center, the temperature changes by $4 \mathrm{~K}$ within a distance of $60 \mathrm{~km}$ along $100 \mathrm{~km}$ west, and results in cold advection. Dropsondes released in this region show a wind that backs with height, indicating that coldair advection existed between the surface and $850 \mathrm{hPa}$ (Fig. 7a). At 3-km height, the temperature gradient to the west of the low-level center (Fig. 5) was much weaker than at $1.5-\mathrm{km}$ height. To the north and northeast of the low-level center the temperature change still exceeds values of $5 \mathrm{~K}$ within a distance of $100 \mathrm{~km}$ along $100 \mathrm{~km}$ west. Thus, there is a remarkable asymmetry in the temperature field. The temperature gradient to the northeast of the low-level center is associated with 


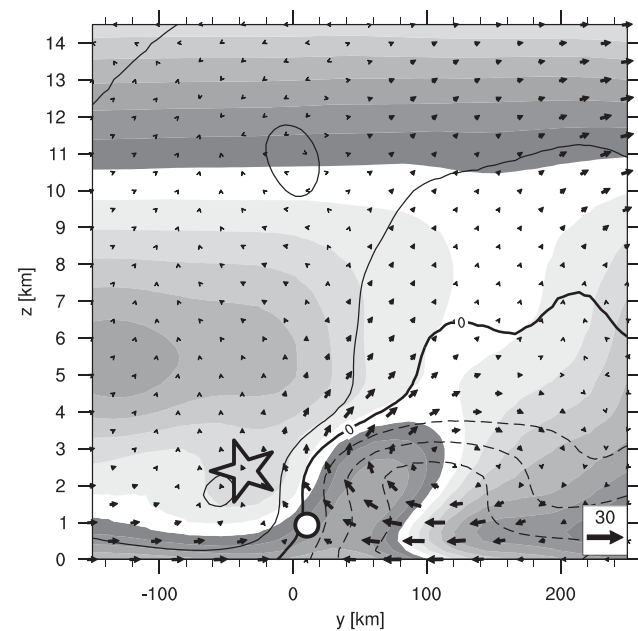

(a)

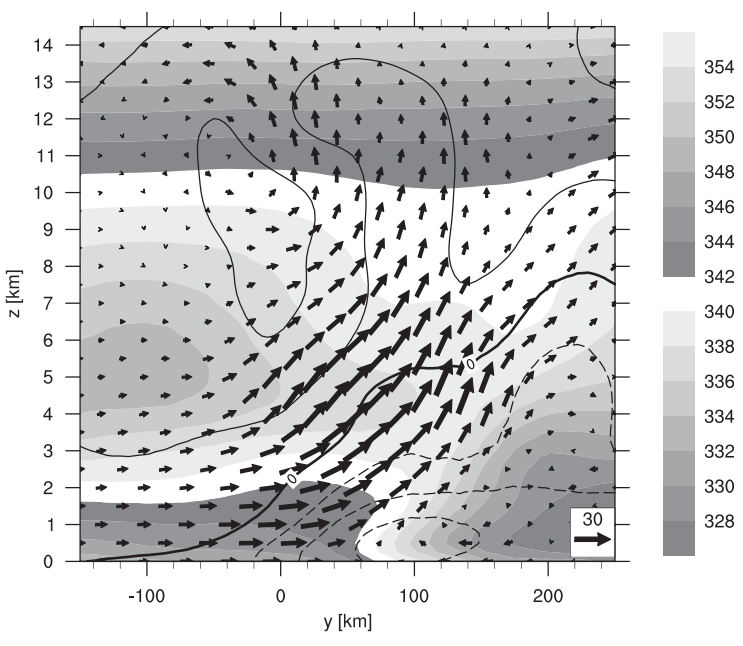

(b)

FIG. 8. Moist static energy ( $\mathrm{kJ} \mathrm{kg}^{-1}$; shaded) along (a) $40 \mathrm{~km}$ east and (b) $160 \mathrm{~km}$ east. Wind vectors are parallel to cross section $\left(\mathrm{m} \mathrm{s}^{-1}\right)$. Here $w$ is multiplied by 10 . Contours denote wind component perpendicular to the cross section $\left(\mathrm{m} \mathrm{s}^{-1}\right.$; contour interval of $\left.10 \mathrm{~m} \mathrm{~s}^{-1}\right)$. Dashed contours are negative values. The black star indicates the position of the dry intrusion and the white circle indicates the circulation center at 1-km height.

a horizontal wind shift and was collocated with the stratiform precipitation region.

A region of temperatures greater than $294 \mathrm{~K}$ at $1.5-\mathrm{km}$ height (Fig. 4) and $286 \mathrm{~K}$ at 3-km height (Fig. 5) can be identified in westerly flow between $100 \mathrm{~km}$ south and $0 \mathrm{~km}$ north, and between $80 \mathrm{~km}$ west and $80 \mathrm{~km}$ east. To the south of the low-level center, a dropsonde measurement (Fig. 7c) indicates a warm-moist layer in the lowest $50 \mathrm{hPa}$ with southwesterly winds. Above, a rather dry layer exists with a dewpoint depression of $10 \mathrm{~K}$ and westerly winds. A strong inversion of $5 \mathrm{~K}$ and an almost dry adiabatic lapse rate indicate descending air above $950 \mathrm{hPa}$. The dropsonde data support the trajectory calculations in section 3 that indicate descending air in this region. Also, satellite imagery indicates a region of dry air wrapping around the southern part of the cyclone (Fig. 2). Therefore it can be assumed that the strong inversion between the low-level moist tropical air and the dry intrusion above led to a region of enhanced convective inhibition. This feature suppressed the development of a convectively active cold front.

The SAMURAI analysis represents the dynamic and thermodynamic structure in this region quite well. In particular, the dewpoint profile in the SAMURAI analysis is consistent with the dropsonde measurement. The strong vertical gradients in temperature due to the inversion are not precisely represented in the SAMURAI analysis. The reasons for the underestimation of the vertical gradients are both a limited a vertical resolution of $0.25 \mathrm{~km}$ and a $0.5-\mathrm{km}$ vertical Gaussian filter used to smooth the analysis.
As described in section 3, the dry air reached the eastern part of the low-level center shortly before the convective development. We assess the impact of the dry intrusion on the static stability by investigating the moist static energy, which is defined as $h=c_{p} T+g z+$ $L_{v} q$. Here $c_{p}$ is the specific heat at constant pressure, $g$ is the gravitational acceleration, $z$ is the altitude, $L_{v}$ is the latent heat of vaporization, and $q$ is the water vapor mixing ratio. A vertical cross section of moist static energy along $40 \mathrm{~km}$ east, which is at the location of the dropsonde in Fig. 7c, illustrates the dry intrusion between 100 and $0 \mathrm{~km}$ south, and between $1-$ and $3-\mathrm{km}$ height (Fig. 8a). The warm-moist tropical layer can be identified below 1-km height in a southwesterly flow.

A vertical cross section of the wind field and moist static energy (Fig. 8a) indicates that Sinlaku's circulation center at $1-\mathrm{km}$ height is located in the region of the strongest horizontal gradient in moist static energy. Above 1-km height, the southern part of the circulation is characterized by rather dry air while the northern part is characterized by moist air. These two features lead to a remarkable asymmetry. The presence of moist air to the north of the circulation center (20-80 km north) and up to 4-km height can be attributed to advection since moist static energy is approximately conserved. The results suggest that moist air is advected vertically within the deep convection and advected horizontally to the north of the circulation center in an easterly flow. The primary midlatitude baroclinic zone is marked clearly by the strong change of $14 \mathrm{~kJ} \mathrm{~kg}^{-1}$ in moist static energy between 80 and $120 \mathrm{~km}$ north. The northeasterly flow at low levels indicates 
advection of cold air around the cyclone into the coldfrontal region and therefore coincides with the backing winds in the dropsonde profile (Fig. 7a).

The southern part of the analyzed domain exhibits a potentially unstable stratification due to midlevel cold and dry air above tropical warm-moist air. This instability is maximized in the region of the dry intrusion. Forced ascent in this region would lift the dry intrusion and release the potential instability. According to satellite imagery (section 3), the deep convection developed on the leading edge of the dry intrusion. Therefore, we assume that forced ascent in this potentially unstable environment triggered the deep convective development. A possible mechanism that contributed to the triggering is discussed in section 5 .

In the region of the convection, the structure of the moist static energy is rather similar, although differing in some points (Fig. 8b). The dry intrusion between 1- and 3-km height does not exist. Nevertheless, midlevel dry air causes potential instability. In the deep convective region (i.e., south of $100 \mathrm{~km}$ north, potential instability remains but vanishes north of $100 \mathrm{~km}$ north). Along $100 \mathrm{~km}$ north the stratification is almost neutral, probably as a result of vertical advection of warm-moist air in the deep convection. A stable stratification due to a low-level cold easterly flow characterizes the stratiform precipitation region. The slantwise ascent described earlier is almost parallel to the moist isentropes of the baroclinic zone.

The slantwise ascent of warm-moist air and the dry intrusion identified in the observational data indicate the development of extratropical flow characteristics during the ET of TY Sinlaku. As illustrated in section 3, the airflows strongly resemble the conceptual model of airflows through a midlatitude wave cyclone (Carlson 1980). The slantwise ascent of warm-moist air in northerly directions indicates a warm conveyor belt. Dry midlatitude air, which descends to the west of the cyclone and flows over the warm-moist southerly flow, characterizes a dry tongue jet as defined by Carlson (1980). The low-level cold easterly flow to the north of the low-level center strongly resembles a cold conveyor belt. However, we did not observe in the SAMURAI analysis region that this airflow ascended anticyclonically to the north of the low-level center. The main difference to the conceptual model of Carlson (1980) is the development of the deep convective system with strong updrafts east of the low-level center. These strong updrafts and the height of the convective system are suggestive of remnant TC characteristics. The coexistence of midlatitude and tropical features nicely illustrates the transition from a purely tropical to an extratropical system.

\section{Structural mechanisms}

In the previous section the structural characteristics of Sinlaku and its environment have been described. Four important questions arise from these examinations. First, the impact of the circulation of Sinlaku on its local environment needs to be assessed. Second, possible mechanisms that triggered the deep convection have to be investigated. Third, the influence of the deep convection on the environmental flow and the remnant potential vorticity (PV) tower has to be considered. Finally, the extent to which the relevant mechanisms are represented in the operational ECMWF analysis has to be assessed.

\section{a. Frontogenesis}

We described the horizontal and vertical structure of the temperature and wind field by using the SAMURAI analysis and dropsonde measurements (see section 4). Horizontal wind shifts and strong temperature gradients were found west and northeast of the low-level center (Fig. 4). These gradients were associated with backing winds to the west of the low-level center (Fig. 7a) and with veering winds to the northeast of the low-level center (Fig. 7b). These features indicate a cold-frontal and warm-frontal zone, respectively. We assess the impact of the circulation of Sinlaku on the temperature field by calculating the frontogenesis components $F_{n}$ and $F_{s}$ (Keyser et al. 1988) with

$$
\begin{aligned}
& F_{n}=-|\nabla \theta|^{-1}[\underbrace{\frac{\partial \theta}{\partial x}\left(-\frac{\partial u}{\partial x} \frac{\partial \theta}{\partial x}-\frac{\partial v}{\partial x} \frac{\partial \theta}{\partial y}\right)}_{F_{n}-\operatorname{div}}+\underbrace{\frac{\partial \theta}{\partial y}\left(-\frac{\partial u}{\partial y} \frac{\partial \theta}{\partial x}-\frac{\partial v}{\partial y} \frac{\partial \theta}{\partial y}\right)}_{F_{n}-\text { def }}], \text { and } \\
& F_{s}=-|\nabla \theta|^{-1}[\underbrace{\frac{\partial \theta}{\partial y}\left(-\frac{\partial u}{\partial x} \frac{\partial \theta}{\partial x}-\frac{\partial v}{\partial x} \frac{\partial \theta}{\partial y}\right)}_{F_{s}-\text { vor }}-\underbrace{\frac{\partial \theta}{\partial x}\left(-\frac{\partial u}{\partial y} \frac{\partial \theta}{\partial x}-\frac{\partial v}{\partial y} \frac{\partial \theta}{\partial y}\right)}_{F_{s} \text {-def }}],
\end{aligned}
$$




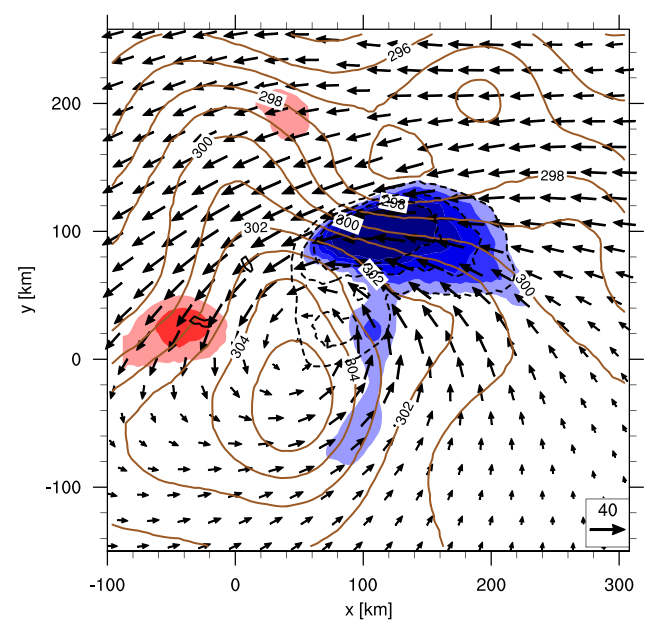

(a)

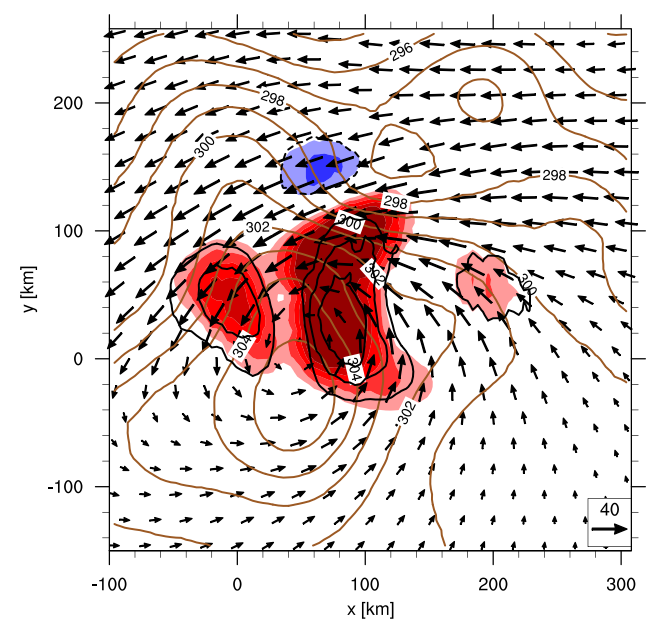

(c)

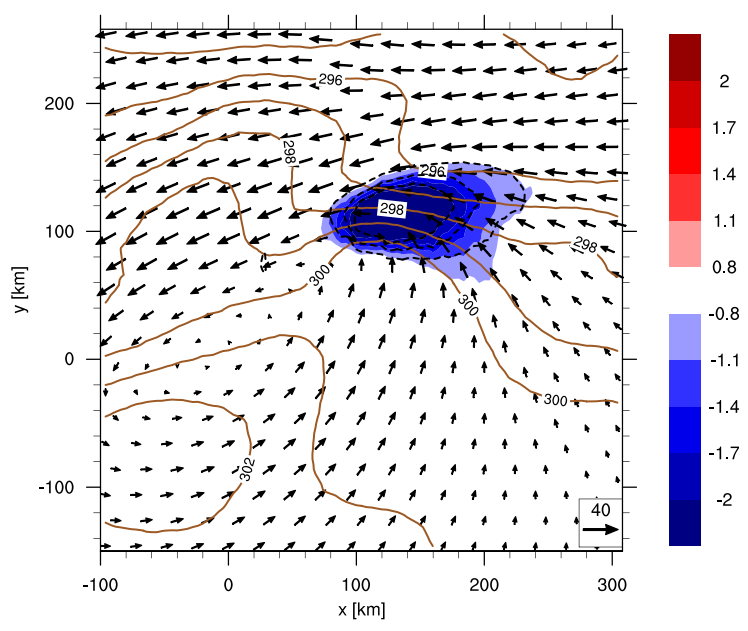

(b)

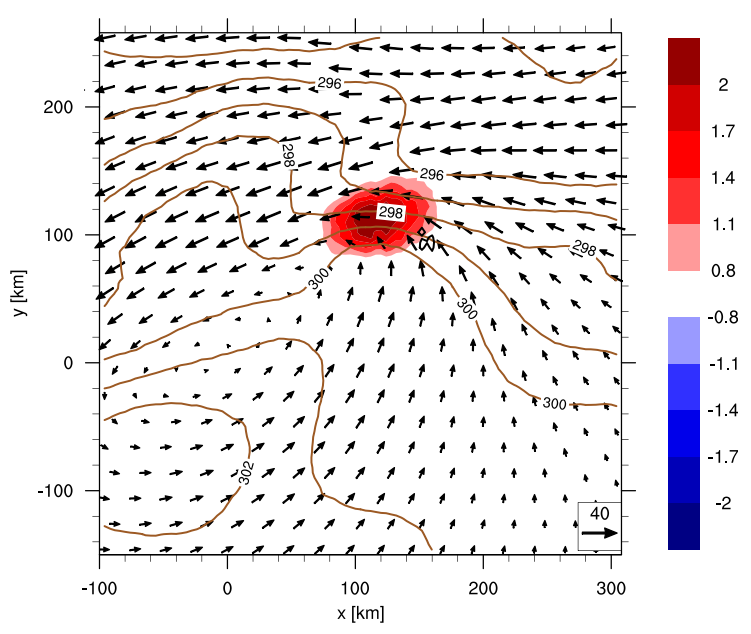

(d)

FIG. 9. (a),(b) $F_{n}$ and (c),(d) $F_{s}\left(10^{-8} \mathrm{~K} \mathrm{~m}^{-1} \mathrm{~s}^{-1}\right)$ at $1 \mathrm{~km}$ (shaded). Black contours are (a),(b) $F_{n}$-def and (c),(d) $F_{s}$-def in increments of $0.6 \times 10^{-8} \mathrm{~K} \mathrm{~m}^{-1} \mathrm{~s}^{-1}$ starting at $0.8 \times 10^{-8} \mathrm{~K} \mathrm{~m}^{-1} \mathrm{~s}^{-1}$ and $-0.8 \times 10^{-8} \mathrm{~K} \mathrm{~m}^{-1} \mathrm{~s}^{-1}$, respectively. Negative values are dashed. Wind vectors give horizontal wind $\left(\mathrm{m} \mathrm{s}^{-1}\right)$ and brown contours denote potential temperature (K) at $1 \mathrm{~km}$. (a),(c) From SAMURAI and (b),(d) from the ECMWF analysis.

where $\theta$ is the potential temperature. The scalar frontogenesis $F_{n}$ defines the magnitude of the Lagrangian rate of change of the horizontal $\theta$ gradient. The rotational frontogenesis $F_{s}$ gives the Lagrangian rate of change of the direction of the horizontal $\theta$ gradient.

Scalar frontogenesis, defined by negative $F_{n}$, occurs to the northeast of the low-level center in the warm-frontal region (Fig. 9a). Weak scalar frontolysis occurs to the west of the low-level center in the cold-frontal region. By dividing $F_{n}$ into frontogenesis due to deformation $\left(F_{n}\right.$-def $)$ and frontogenesis due to divergence $\left(F_{n}\right.$-div $)$ (Harr and Elsberry 2000) we can assess the impact of the circulation of Sinlaku on the temperature field. The cyclonic wind field associated with Sinlaku, $F_{n}$-def, contributes most strongly to the warm frontogenesis (Fig. 9a), which is consistent with warm frontogenesis when a cyclonic vortex is placed on a temperature gradient (Keyser et al. 1988). The contribution of $F_{n}$-div is negligible (not shown).

Rotational frontogenesis, defined by positive $F_{s}$, extends around the northern portion of the low-level center (Fig. 9c). It is associated with a thermal ridge to the northwest of the low-level center and a thermal trough to the west of the low-level center. An examination of the contributions to $F_{s}$ from relative vorticity $\left(F_{s}\right.$-vor $)$ and from deformation $\left(F_{s}\right.$-def) indicates that deformation dominates (Fig. 9c). Contributions by $F_{s}$-vor occur solely to the northeast of the low-level 
center in the warm-frontal region (not shown). The situation indicates a deepening thermal trough to the west and an amplifying thermal ridge to the northeast of the low-level center. Furthermore, the misalignment of maximum $F_{s}$ and the axes of the thermal trough and the thermal ridge indicates an eastward propagation of the thermal wave.

The wind and temperature fields of the ECMWF analysis exhibit two main differences to the SAMURAI analysis. First, the wind field at 1-km height (Fig. 9b) is weaker and quite asymmetric with an elliptic circulation and a strong horizontal wind shift to the northeast of the circulation center. Second, an anomaly in potential temperature to the south of the low-level center, associated with the dry intrusion in the SAMURAI analysis, cannot be found in the ECMWF analysis. In the ECMWF analysis the potential temperature anomaly is displaced to the southwest compared to the observational analysis. Because of an underestimation of the pressure at 1-km height (not shown) the potential temperature exhibits lower values in the ECMWF analysis. The differences described have noticeable implications for the frontogenesis.

The structure of $F_{n}$ derived from the ECMWF analysis is similar to that of the SAMURAI analysis. A stronger horizontal wind shift in the ECMWF analysis leads to slightly stronger scalar frontogenesis in the warm-frontal region. The $F_{n}$-def dominates scalar frontogenesis (Fig. 9b). Frontolysis in the cold-frontal region does not occur in the analyzed domain due to a weaker gradient in potential temperature and the fact that winds are nearly parallel to the temperature gradient in the cold-frontal region.

The $F_{s}$ is much weaker in the ECMWF analysis than in the SAMURAI analysis (Fig. 9d). The reason for this underestimation in the ECMWF analysis is an inaccurate representation of the temperature anomaly associated with the dry intrusion. This leads to a weakening of the meridional temperature gradient and a much weaker $F_{s}$-def to the east of the low-level center. A region of positive $F_{s}$-vor (not shown) to the northeast of the low-level center indicates an impact on the temperature field (i.e., an amplification of the thermal wave). This $F_{s}$-vor pattern exhibits a similar magnitude to that in the SAMURAI analysis.

\section{b. Q-vector forcing}

We evaluate the role of synoptic-scale forcing of ascent in the frontal region and in the deep convection by calculating the Q-vector forcing (Hoskins et al. 1978; Martin 1999). We assume that the pressure-based vertical coordinate, $z$, is identical with physical height. Considerably more wind observations than pressure observations are included in the SAMURAI analysis, so that the confidence in the wind field is higher than that in the pressure field. Thus, we approximate the geostrophic wind by the total wind field. As a third simplification we neglect diabatic effects. With these assumptions, upward motion is forced by the convergence of $\mathbf{Q}$ (Hoskins et al. 1978) with

$\mathbf{Q}=-\frac{R}{p_{0}}\left(\frac{p_{0}}{p}\right)^{c_{v} / c_{p}}\left[\left(\frac{\partial \mathbf{V}_{g}}{\partial x} \cdot \nabla \theta\right) \mathbf{i}+\left(\frac{\partial \mathbf{V}_{g}}{\partial y} \cdot \nabla \theta\right) \mathbf{j}\right]$.

To simplify the interpretation we partition $\mathbf{Q}$ into

$$
\mathbf{Q}_{s}=\frac{\mathbf{Q} \cdot(\mathbf{k} \times \nabla \theta)}{|\mathbf{\nabla} \theta|}\left(\frac{\mathbf{k} \times \nabla \theta}{|\nabla \theta|}\right),
$$

which is parallel to the isentropes and

$$
\mathbf{Q}_{n}=\left(\frac{\mathbf{Q} \cdot \mathbf{\nabla} \theta}{|\nabla \theta|}\right) \frac{\boldsymbol{\nabla} \theta}{|\mathbf{\nabla} \theta|},
$$

which is perpendicular to the isentropes. Similar to the frontogenesis partition $\mathbf{Q}_{n}$ affects the change in the magnitude of the horizontal $\theta$ gradient and $\mathbf{Q}_{s}$ affects the change of the direction of the horizontal $\theta$ gradient. This allows us to assess the influence on vertical motion and on the temperature field separately.

At 1-km height (Fig. 10a), there are banded regions of $\mathbf{Q}_{n}$ convergence and divergence that are nearly parallel to the isentropes in the region of strongest baroclinicity. Divergence of $\mathbf{Q}_{n}$ exists in the northern part and convergence of $\mathbf{Q}_{n}$ in the southern part of the baroclinic zone. The dipole structure of $\mathbf{Q}_{n}$ is maintained up to $3.5-\mathrm{km}$ height (not shown). These banded regions of Q-vector forcing have been documented in midlatitude cyclones (e.g., Barnes and Colman 1993). At 1-km height, the maximum of $\mathbf{Q}_{n}$ convergence is located between 50 and $90 \mathrm{~km}$ north and 50 to $120 \mathrm{~km}$ east and thus collocated with the deep convective region that developed on the leading edge of the dry intrusion according to the satellite imagery. This indicates that the $\mathbf{Q}$-vector forcing of vertical motion led to ascent in the initially potentially unstable environment associated with the dry intrusion and triggered the deep convection. In addition, the frontogenetical process forced the development of a thermally direct circulation in the warm-frontal region.

The low-level structure of the $\mathbf{Q}_{s}$ convergence indicates an impact on the temperature field (Fig. 10c). Strongest $\mathbf{Q}_{s}$ divergence is collocated with a thermal trough to the north of the low-level center. Regions with $\mathbf{Q}_{s}$ convergence are located to the east of this divergent region in a rather zonally oriented temperature gradient. 


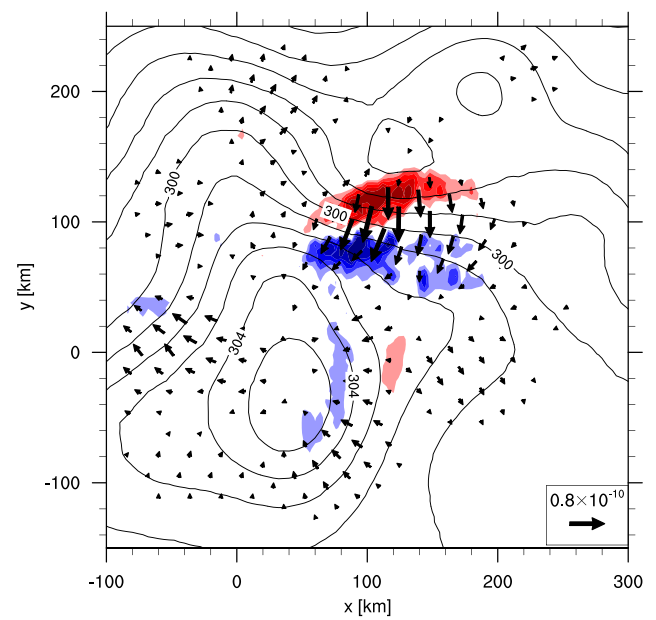

(a)

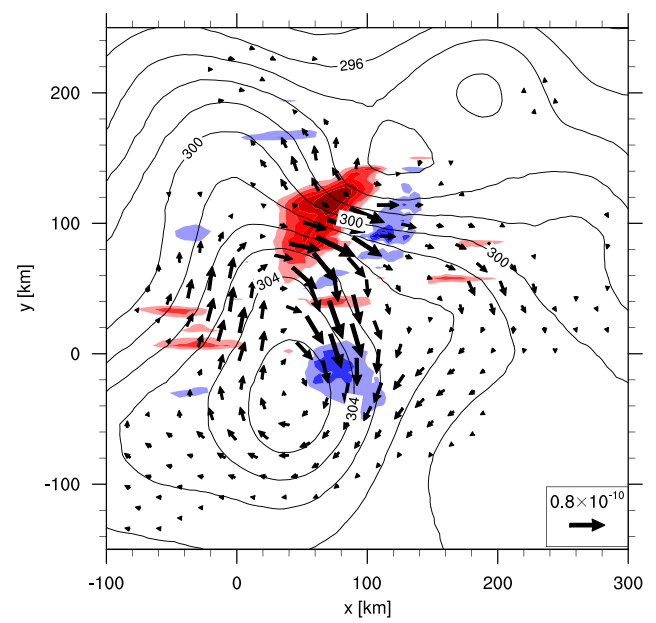

(c)

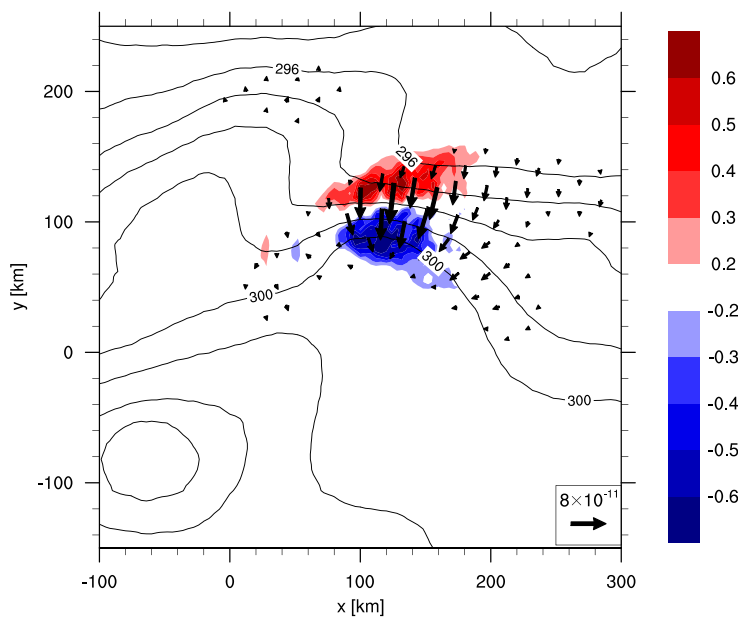

(b)

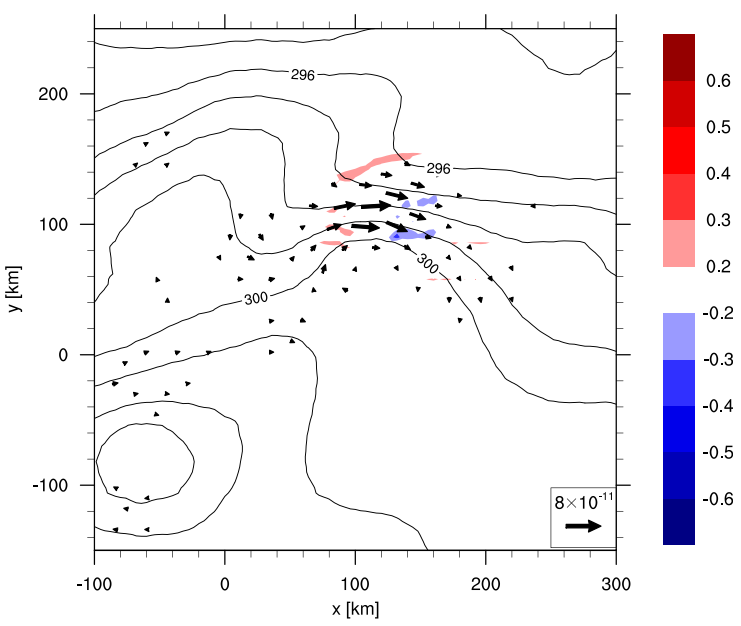

(d)

FIG. 10. Vectors ( $\left.\mathrm{K} \mathrm{m}^{-1} \mathrm{~s}^{-1}\right)$ and divergence of (a),(b) $\mathbf{Q}_{n}\left(10^{-14} \mathrm{~m} \mathrm{~kg}^{-1} \mathrm{~s}^{-1}\right)$ and (c),(d) $\mathbf{Q}_{s}$ at $1 \mathrm{~km}$. Vectors with a magnitude of less than $8 \times 10^{-12} \mathrm{~K} \mathrm{~m}^{-1} \mathrm{~s}^{-1}$ are not shown. Contours are potential temperature (K) at $1 \mathrm{~km}$. (a),(c) From SAMURAI and (b),(d) from the ECMWF analysis.

As for the frontogenesis pattern, the observed structure amplifies the thermal wave with a deepening thermal trough. Furthermore, the $\mathbf{Q}_{s}$ convergence maximum provides $\mathbf{Q}$-vector forcing for upward motion. The observed structures would predict a deepening in the case of a midlatitude low. According to the ECMWF analysis, Sinlaku intensified by $4 \mathrm{hPa}$ in the following $12 \mathrm{~h}$. Nevertheless, Sinlaku did not reintensify to a major extratropical low pressure system.

A similar structure of $\mathbf{Q}_{n}$ convergence and divergence can be identified in the ECMWF analysis (Fig. 10b). A dipole structure of $\mathbf{Q}_{n}$ (i.e., a banded region of $\mathbf{Q}$-vector forcing) exists along a region of maximized temperature gradient and indicates, as in the SAMURAI analysis, the forcing of a thermally direct circulation across the front. The maximum of $\mathbf{Q}_{n}$ convergence is displaced in an easterly direction and is slightly stronger than in the SAMURAI analysis. The structure predicts a strengthening of the amplitude of the temperature gradient and the forcing of vertical motion similar to the SAMURAI analysis.

The $\mathbf{Q}_{s}$ convergence is weaker than in the SAMURAI analysis (Fig. 10d). Furthermore, the $\mathbf{Q}_{s}$ divergence is not collocated with the thermal trough to the north of the cyclone. Only small artifacts of $\mathbf{Q}_{s}$ convergence in the thermal ridge predict a weak amplification of the thermal wave. The differences in $\mathbf{Q}_{s}$ forcing result from differences in the potential temperature field. As discussed in section 5a, the dry intrusion is displaced to the southwest in the ECMWF analysis, which results in 


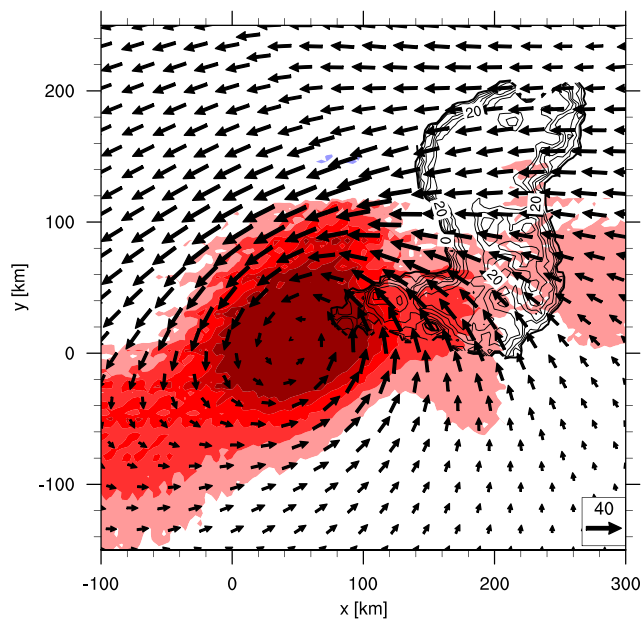

(a)

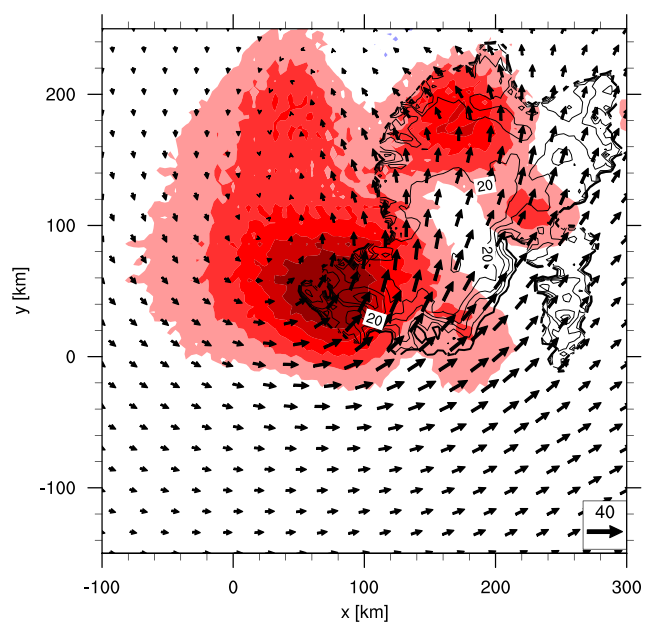

(c)

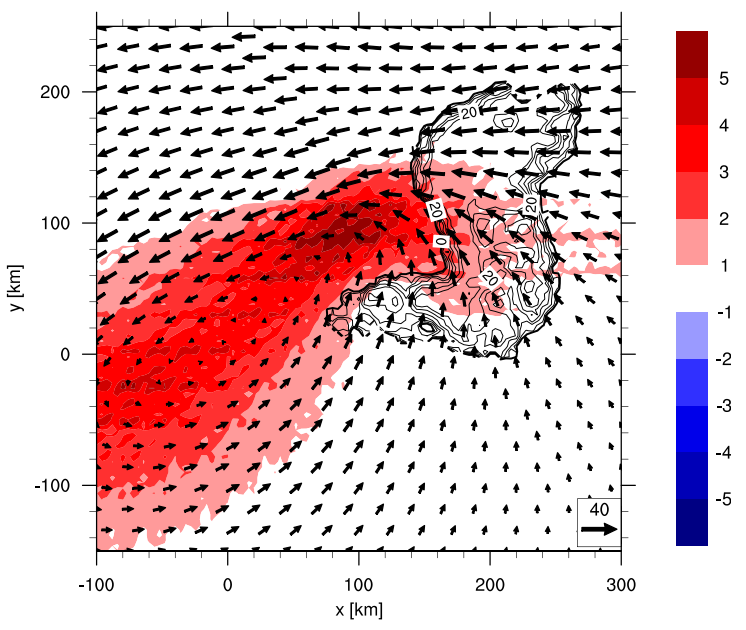

(b)

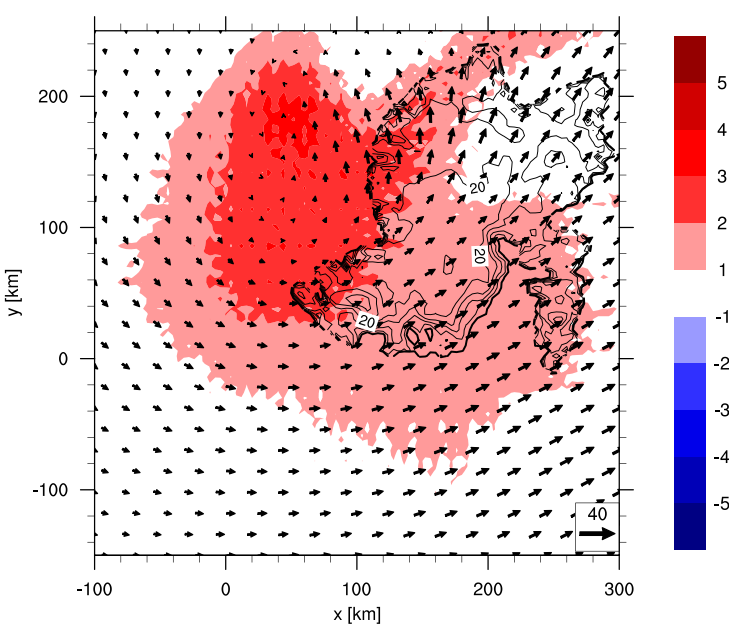

(d)

FIG. 11. Potential vorticity (PVU; shaded) and reflectivity (dBZ; contours) at (a),(b) $1 \mathrm{~km}$ and (c),(d) $6 \mathrm{~km}$. (a),(c) From SAMURAI analysis and (b),(d) from ECMWF analysis. Wind vectors give horizontal wind ( $\left.\mathrm{m} \mathrm{s}^{-1}\right)$ at (a),(b) $1 \mathrm{~km}$ and (c),(d) $6 \mathrm{~km}$. In (b) and (d) reflectivity is given only for orientational purposes.

a much weaker temperature gradient and weaker forcing by $\mathbf{Q}_{s}$ convergence and divergence.

\section{c. Potential vorticity}

We assess the influence of the deep convection on the transitioning typhoon and its associated PV tower by evaluating the PV structure. The PV is calculated as $\mathrm{PV}=\rho^{-1}\left[(\zeta+f) \theta_{z}-v_{z} \theta_{x}+u_{z} \theta_{y}\right]$

The low-level PV was characterized by a strong positive PV anomaly associated with Sinlaku's circulation center, with values exceeding 5 potential vorticity units (PVU) (1 PVU $=1 \times 10^{-6} \mathrm{~K} \mathrm{~kg}^{-1} \mathrm{~m}^{2} \mathrm{~s}^{-1}$; Fig. 11a). The $\mathrm{PV}$ anomaly was elongated, with higher $\mathrm{PV}$ values to the west-southwest of the circulation center. This asymmetry was caused by a wind shift from northerly to westerly winds in the cold-frontal region. Because of the dry intrusion the vertical extent of the developing cold front was limited to the lower troposphere. The ECMWF analysis exhibits a much weaker and more asymmetric PV anomaly at low levels (Fig. 11b). This anomaly was associated with a southwest-northeast-elongated lowlevel circulation. In contrast to the SAMURAI analysis, the PV maximum was not collocated with the circulation center but with a strong wind shift in the warmfrontal zone.

The low-level PV anomaly associated with the lowlevel center decreased with height and was at a minimum at 3-km height (not shown). Above $3 \mathrm{~km}$ the PV increased in the deep convective region resulting in a second PV maximum at 6-km height of more than 5 PVU 


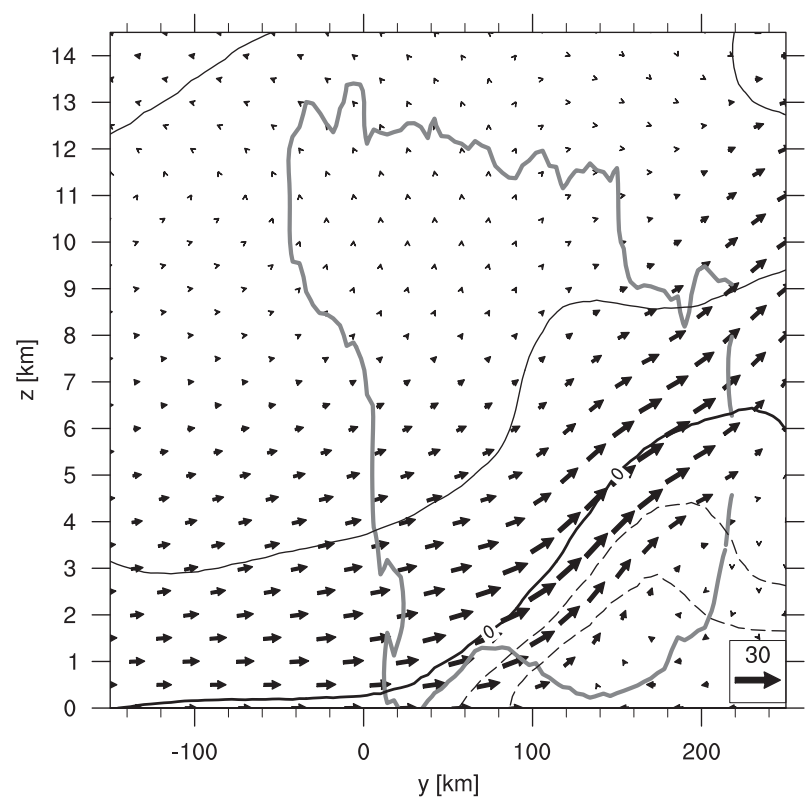

FIG. 12. As in Fig. 6b, but derived from ECMWF analysis. Gray contour denotes reflectivity from SAMURAI analysis for orientational purposes.

(Fig. 11c). At this height the PV maximum was found in the region of the highest reflectivity values and was therefore associated with the deep convection. The wind field at $6-\mathrm{km}$ height was characterized by a cyclonic but open circulation in the analyzed domain. We attribute this open circulation to the remnant midtropospheric circulation associated with Sinlaku. The axis of this open circulation was collocated with the maximum of PV and accordingly with the deep convection. We suggest that latent heat release due to continuous condensation in the deep convective region led to a production of PV. The PV anomaly strengthened the southern part of the remnant midtropospheric circulation associated with Sinlaku.

The PV structure in the ECMWF analysis differs considerably. There are no PV values exceeding 3 PVU at 6-km height (Fig. 11d). The wind field in the operational ECMWF analysis exhibits a slantwise ascent into the midtroposphere in the analyzed domain (Fig. 12). This slantwise ascent coincides with the $\mathbf{Q}$ vectors derived from the operational ECMWF analysis that indicate a synoptic-scale forcing for upward motion (Fig. 10b). Likewise, the SAMURAI analysis exhibits this slantwise ascent in conjunction with the quasigeostrophic forcing (Fig. 6b). Additionally, we identified nearly upright ascent in the region of the deep convection throughout the complete troposphere in the SAMURAI analysis. In the ECMWF analysis we do not find this strong, upright ascent in the region of the deep convection. This indicates that the operational ECMWF analysis does not capture the deep convection adequately. Hence, the PV production due to persistent latent heat release does not occur at 6-km height. As a result, the modification of the remnant midtropospheric circulation associated with Sinlaku is considerably weaker than in the SAMURAI analysis.

\section{Discussion}

Using operational ECMWF analyses and highresolution observational data from T-PARC, we describe the multiscale structure of TY Sinlaku and its environment during the transformation stage of ET on 20 September 2008. In particular, the observational data are unique: two research aircraft documented simultaneously for the first time during T-PARC the structure of an ET system during its transformation stage.

A nearly zonally oriented midlatitude flow at upper levels and a midlatitude low pressure system to the northeast of Sinlaku characterized the synoptic situation during the ET of Sinlaku. Therefore, Sinlaku did not encounter favorable conditions for an extratropical reintensification. The calculation of 48 -h backward trajectories shows that midlatitude dry air masses and tropical moist air masses were advected toward the cyclone. The overflow of the midlatitude air masses over the tropical air masses led to a significant destabilization and therefore favored the conditions for convective activity. According to satellite imagery, these airflow characteristics formed between the T-PARC flights on 19 and 20 September as part of the documentation of the ET process (Foerster et al. 2013, manuscript submitted to Mon. Wea. Rev.). The development and orientation of these air masses were similar to those of the dry tongue jet and the warm conveyor belt in typical midlatitude wave cyclones.

Satellite imagery showed a deep convective development as Sinlaku approached the midlatitude baroclinic zone. Two research aircraft equipped with dropsondes and ELDORA investigated this convective event. We used the observational data from these research flights and the recently developed data assimilation tool SAMURAI to derive a three-dimensional analysis of the transitioning typhoon and its environment. The analysis allows different features such as deep convection, a stratiform precipitation region, warm- and coldfrontal structures, and a dry intrusion to be identified.

The dry intrusion enhanced potential instability to the east of the low-level center due to dry, midlatitude air above moist tropical air. The SAMURAI analysis shows that the deep convection developed on the warm-frontal zone in this potentially unstable environment. The deep convection was characterized by multiple convective 
cells. The northern part of the radar analysis exhibited a stratiform precipitation character that was characterized by homogeneous but strong precipitation. In the convective region nearly upright vertical motion could be identified up to the cirrus shield. In contrast, slantwise ascent along the moist isentropes of the baroclinic zone characterized the ascent in the stratiform precipitation region.

We evaluated $\mathbf{Q}$-vector forcing to assess the influence of frontogenetical processes on the convective development and to investigate the interaction between the dry intrusion and the frontogenetical processes. The $\mathbf{Q}$ vectors suggest that the warm-frontal development, documented by scalar frontogenesis, led to forced ascent in a potentially unstable environment and triggered deep convective development. Additionally, the $\mathbf{Q}$ vectors indicate an amplification of the temperature gradient and an amplification of the thermal wave associated with the interaction of the cyclone with a zonally orientated baroclinic zone.

The influence of the convection on Sinlaku was assessed through an examination of the PV structure. At the lowest levels the PV maximum was collocated with Sinlaku's residual low-level center. A second PV maximum existed in the midtroposphere in the deep convective region. This maximum was a result of latent heat release within the deep convection that distorted the environmental wind field. The structure is consistent with the PV-based conceptual model of ET that has been described by AgustiPanareda et al. (2004). The ECMWF analysis does not represent the vertical motion in the deep convective region adequately. The deficiency suggests that the PV production by latent heat release was too weak in the operational ECMWF analysis resulting in a weaker midlevel PV anomaly than in the SAMURAI analysis.

The development of a convectively active cold front could not be observed in our analysis. The air at low altitudes was cooler than in the warm-frontal region, which decreased the potential instability. Furthermore, weaker frontogenesis in the cold-frontal region provided less forcing for vertical motion so that the deep convection could not be triggered. According to the SAMURAI analysis, cold-frontal structures were limited to the lower troposphere, which is consistent with the findings of Harr and Elsberry (2000).

Our results suggest that complex interactions between tropical and extratropical air masses on the mesoscale played an important role during Sinlaku's ET. The deep convective development that resulted from these interactions was not adequately resolved by the operational ECMWF analysis. This indicates that an inaccurate representation of mesoscale features in the analysis state of a global model might have adverse implications on the forecast of an ET system. In particular the combined effects of both tropical air masses and midlatitude mechanisms seem to pose considerable difficulties. In a future study, we will investigate the observed developments with high-resolution simulations that represent the temporal evolution. From these simulations we will assess the importance of the observed mesoscale features on the further development and the forecast of Sinlaku.

Acknowledgments. This project was supported by the German Research Foundation (DFG) as part of the research unit PANDOWAE (FOR896). This work benefited significantly from a visit of the first author to the Naval Postgraduate School, Monterey, which was funded by the Helmholtz Foundation ATMO Program. Author Patrick A. Harr was supported by the National Science Foundation Grant ATM-0736003 and the Office of Naval Research, Marine Meteorology Grant N0001412AF00002. Author Michael M. Bell was supported by the National Science Foundation Grant AGS-085177 and the Office of Naval Research, Marine Meteorology Grant N001408WR20129. T-PARC was sponsored by an international consortium from the United States (National Science Foundation, Office of Naval Research, Naval Research Laboratory, Air Force), Germany (DLR, Forschungszentrum Karlsruhe), Japan (Japan Meteorological Agency), Korea (National Institute of Meteorological Research), and Canada (Environment Canada). The role of the National Center for Atmospheric Research Earth Observing Laboratory (NCAR EOL) in the campaign and data management is acknowledged. We are grateful to Chris Davis for helpful discussions. We are thankful to two anonymous reviewers who helped to improve an earlier version of the manuscript. We thank ECMWF for access to the operational analyses through the special project "The Impact of Tropical Cyclones on Extratropical Predictability."

\section{REFERENCES}

Abraham, J., J. W. Strapp, C. Fogarty, and M. Wolde, 2004: Extratropical transition of Hurricane Michael: An aircraft investigation. Bull. Amer. Meteor. Soc., 85, 1323-1339, doi:10.1175/BAMS-85-9-1323.

Agusti-Panareda, A., C. D. Thorncroft, G. C. Craig, and S. L. Gray, 2004: The extratropical transition of Hurricane Irene (1999): A potential-vorticity perspective. Quart. J. Roy. Meteor. Soc., 130, 1047-1074, doi:10.1256/qj.02.140.

Anwender, D., P. A. Harr, and S. C. Jones, 2008: Predictability associated with the downstream impacts of the extratropical transition of tropical cyclones: Case studies. Mon. Wea. Rev., 136, 3226-3247, doi:10.1175/2008MWR2249.1.

Archambault, H. M., L. F. Bosart, and D. Keyser, 2007: Recurving typhoons as precursors to an early season arctic outbreak over 
the continental U.S. Ninth Northeast Regional Operational Workshop, Albany, NY, National Weather Service/Amer. Meteor. Soc., 1-55. [Available online at http://cstar.cestm. albany.edu/nrow/nrow9/Archambault/archambault.ppt.]

Atallah, E. H., and L. F. Bosart, 2003: The extratropical transition and precipitation distribution of Hurricane Floyd (1999). Mon. Wea. Rev., 131, 1063-1081, doi:10.1175/ 1520-0493(2003)131<1063:TETAPD > 2.0.CO;2.

Barnes, S. L., and B. R. Colman, 1993: Quasigeotrophic diagnosis of cyclogenesis associated with a cutoff extratropical cyclone: The Christmas 1987 storm. Mon. Wea. Rev., 121, 1613-1634, doi:10.1175/1520-0493(1993)121<1613:QDOCAW>2.0.CO;2.

Bell, M. M., M. T. Montgomery, and K. E. Emanuel, 2012: Air-sea enthalpy and momentum exchange at major hurricane wind speeds observed during CBLAST. J. Atmos. Sci., 69, 31973222, doi:10.1175/JAS-D-11-0276.1.

Carlson, T. N., 1980: Airflow through midlatitude cyclones and the comma cloud pattern. Mon. Wea. Rev., 108, 1498-1509, doi:10.1175/1520-0493(1980)108<1498:ATMCAT>2.0.CO;2.

Cordeira, J. M., and L. F. Bosart, 2010: The antecedent large-scale conditions of the "Perfect Storms" of late October and early November 1991. Mon. Wea. Rev., 138, 2546-2569, doi:10.1175/ 2010MWR3280.1.

Evans, J. L., J. M. Arnott, and F. Chiaromonte, 2006: Evaluation of operational model cyclone structure forecasts during extratropical transition. Mon. Wea. Rev., 134, 3054-3072, doi:10.1175/MWR3236.1.

Fogarty, C., 2006: The extratropical transition of Tropical Storm Ophelia (2005): Summary of forecasts and meteorological observations. Extended Abstracts, 27th Conf. on Hurricanes and Tropical Meteorology, Monterey, CA, Amer. Meteor. Soc., P6.1. [Available online at https://ams.confex.com/ams/ 27Hurricanes/techprogram/paper_107911.htm.]

Grams, C. M., and Coauthors, 2011: The key role of diabatic processes in modifying the upper-tropospheric wave guide: A North Atlantic case-study. Quart. J. Roy. Meteor. Soc., 137, 2174-2193, doi:10.1002/qj.891.

Harr, P. A., and R. L. Elsberry, 2000: Extratropical transition of tropical cyclones over the western North Pacific. Part I: Evolution of structural characteristics during the transition process. Mon. Wea. Rev., 128, 2613-2633, doi:10.1175/ 1520-0493(2000)128<2613:ETOTCO >2.0.CO; .

- _ — , and T. F. Hogan, 2000: Extratropical transition of tropical cyclones over the western North Pacific. Part II: The impact of midlatitude circulation characteristics. Mon. Wea. Rev., 128, 2634-2653, doi:10.1175/1520-0493(2000)128<2634: ETOTCO $>2.0 . \mathrm{CO} ; 2$.

Hart, R. E., and J. L. Evans, 2001: A climatology of the extratropical transition of Atlantic tropical cyclones. J. Climate, 14, 546-564, doi:10.1175/1520-0442(2001)014<0546:ACOTET>2.0.CO;2.

Hildebrand, P. H., and Coauthors, 1996: The ELDORA/ASTRAIA airborne Doppler weather radar: High-resolution observations from TOGA COARE. Bull. Amer. Meteor. Soc., 77, 213-232, doi:10.1175/1520-0477(1996)077<0213:TEADWR >2.0.CO;2.

Hoskins, B. J., I. Draghici, and H. C. Davies, 1978: A new look at the w-equation. Quart. J. Roy. Meteor. Soc., 104, 31-38, doi:10.1002/qj.49710443903.
Jones, S. C., and Coauthors, 2003: The extratropical transition of tropical cyclones: Forecast challenges, current understanding, and future directions. Wea. Forecasting, 18, 1052-1092, doi:10.1175/1520-0434(2003)018<1052:TETOTC $>2.0 . C O ; 2$.

Keyser, D., M. J. Reeder, and R. J. Reed, 1988: A generalization of Petterssen's frontogenesis function and its relation to the forcing of vertical motion. Mon. Wea. Rev., 116, 762-781, doi:10.1175/ 1520-0493(1988)116<0762:AGOPFF $>2.0 . C O ; 2$.

Klein, P. M., P. A. Harr, and R. L. Elsberry, 2000: Extratropical transition of western North Pacific tropical cyclones: An overview and conceptual model of the transformation stage. Wea. Forecasting, 15, 373-395, doi:10.1175/1520-0434(2000)015<0373: ETOWNP $>2.0 . \mathrm{CO} ; 2$

Martin, J. E., 1999: Quasigeostrophic forcing of ascent in the occluded sector of cyclones and the trowal airstream. Mon. Wea. Rev., 127, 70-88, doi:10.1175/1520-0493(1999)127<0070: QFOAIT $>2.0 . \mathrm{CO} ; 2$.

Polak, E., 1971: Computational Methods in Optimization: A Unified Approach. Academic Press, 321 pp.

Press, W. H., B. P. Flannery, S. A. Teukolsky, and W. T. Vetterling, 2002: Numerical Recipes in C++: The Art of Scientific Computing. Cambridge University Press, 1032 pp.

Quinting, J. F., 2011: Structural characteristics of Typhoon Sinlaku (2008) during its extratropical transition: An observational study. M.S. thesis, Institute of Meteorology and Climate Research, Karlsruhe Institute of Technology, Karlsruhe, Germany, 113 pp. [Available online at http://www.imk-tro.kit.edu/ download/Diplomarbeit_Quinting.pdf.]

Reynolds, C. A., M. S. Peng, and J.-H. Chen, 2009: Recurving tropical cyclones: Singular vector sensitivity and downstream impacts. Mon. Wea. Rev., 137, 1320-1337, doi:10.1175/ 2008MWR2652.1.

Riemer, M., S. C. Jones, and C. A. Davis, 2008: The impact of extratropical transition on the downstream flow: An idealized modelling study with a straight jet. Quart. J. Roy. Meteor. Soc., 134, 69-91, doi:10.1002/qj.189.

Rogers, R., and Coauthors, 2006: The Intensity Forecasting Experiment: A NOAA multiyear field program for improving tropical cyclone intensity forecasts. Bull. Amer. Meteor. Soc., 87, 1523-1537, doi:10.1175/BAMS-87-11-1523.

Sanabia, E. R., 2010: The re-intensification of Typhoon Sinlaku (2008). Ph.D. thesis, Naval Postgraduate School, Monterey, CA, 233 pp. [Available online at http://edocs.nps.edu/npspubs/ scholarly/dissert/2010/Jun/10Jun_sanabia_phd.pdf.]

Vancas, M., 2006: The extratropical transition of Tropical Storm Banyan. M.S. thesis, Dept. of Meteorology, Naval Postgraduate School, Monterey, CA, 90 pp. [Available online at http://edocs.nps.edu/npspubs/scholarly/theses/2006/Sep/ 06Sep_Vancas.pdf.]

Wernli, H., and H. C. Davies, 1997: A Lagrangian-based analysis of extratropical cyclones. I: The method and some applications. Quart. J. Roy. Meteor. Soc., 123, 467-489, doi:10.1002/ qj. 49712353811 .

Wolde, M., D. Marcotte, J. Jordan, J. Aitken, J. Abraham, and J. W. Strapp, 2001: The first Canadian experience with research flight operations in hurricane extratropical transition. Can. Aeronaut. Space J., 47, 179-189. 